\title{
Synergistic Effect of Pistachio Shell Powder and Nano-Zerovalent Copper for Chromium Remediation from Aqueous Solution
}

Sandeep Kumar ( $\nabla$ sandeepchem83@gmail.com )

Akal University https://orcid.org/0000-0002-3969-2097

Ravinderdeep Singh Brar

AKAL UNIVERSITY

J Nagendra Babu

Central University of Punjab

Amarjeet Dahiya

Central University of Punjab

Sandip Saha

Akal University

Avneesh Kumar

Akal University

\section{Research Article}

Keywords: Zerovalent copper, Pistachio, Biomass, $\mathrm{Cr}(\mathrm{VI})$, Adsorption, Kinetics, Synergistic effect

Posted Date: May 4th, 2021

DOI: https://doi.org/10.21203/rs.3.rs-441366/v1

License: (1) This work is licensed under a Creative Commons Attribution 4.0 International License.

Read Full License

Version of Record: A version of this preprint was published at Environmental Science and Pollution Research on July 6th, 2021. See the published version at https://doi.org/10.1007/s11356-021-15285-4. 
1 Synergistic Effect of Pistachio Shell Powder and Nano-Zerovalent Copper for

2 Chromium Remediation from Aqueous Solution

3

4 Sandeep Kumar ${ }^{*}$, Ravinderdeep Singh Brar' ${ }^{1}$, J Nagendra Babu ${ }^{2}$, Amarjeet Dahiya , $5 \quad$ Sandip Saha ${ }^{1}$, Avneesh Kumar ${ }^{3}$

$6 \quad{ }^{1}$ Department of Chemistry, Akal University, Talwandi Sabo, Bathinda-151302, Punjab, INDIA

$7 \quad{ }^{2}$ Department of Chemistry, School of Basic and Applied Science, Central University of Punjab,

8 Bathinda -151 001, Punjab, INDIA

$9 \quad{ }^{3}$ Department of Botany, Akal University, Talwandi Sabo, Bathinda-151302, Punjab, INDIA

10

11 Corresponding Author:

12 Email: sandeepchem83@gmail.com;

13 Telephone: +91-98883-3880.

14 Correspondence Address: Department of Chemistry, Akal University, Talwandi Sabo, Bathinda15 151302, Punjab, INDIA

16

17

18

19

20

21

22

23

24

25 


\section{Abstract}

27 Pistachio shell powder supported nano-zerovalent copper (ZVC@PS) material prepared by borohydride reduction, 28 was characterized using SEM, FTIR, XRD, TGA/DTA, BET, and XPS. SEM, XRD, and XPS revealed the nano29 zerovalent copper to consist of a core-shell structure with $\mathrm{CuO}$ shell and $\mathrm{Cu}(0)$ core with a particle size of 40-100 $30 \mathrm{~nm}$ and spherical morphology aggregated on PS biomass. ZVC@PS was found out to contain 39\% (w/w \%) Cu 31 onto the pistachio shell biomass. Batch sorption of $\mathrm{Cr}(\mathrm{VI})$ from the aqueous using ZVC@PS were studied, and was 32 optimized for dose (0.1-0.5 g/L), initial Cr(VI) concentration(1-20 mg/L) and $\mathrm{pH}$ (2-12). Optimized conditions were $330.1 \mathrm{~g} / \mathrm{L}$ doses of sorbent and $\mathrm{pH}=3$ for $\mathrm{Cr}(\mathrm{VI})$ adsorption. Langmuir and Freundlich adsorption isotherm models 34 fitted well to the adsorption behavior of ZVC@PS for $\mathrm{Cr}(\mathrm{VI})$ with a pseudo-second-order kinetic behavior. 35 ZVC@PS $(0.1 \mathrm{~g} / \mathrm{L})$ exhibits $q_{\max }$ for $\mathrm{Cr}(\mathrm{VI})$ removal up to $111.1 \mathrm{mg} / \mathrm{g}$. XPS and other spectroscopic evidence suggest the adsorption of $\mathrm{Cr}(\mathrm{VI})$ by pistachio shell powder, coupled with reductive conversion of $\mathrm{Cr}(\mathrm{VI})$ to $\mathrm{Cr}(\mathrm{III})$ by $\mathrm{ZVC}$ particles to produce a synergistic effect for the efficient remediation of $\mathrm{Cr}(\mathrm{VI})$ from aqueous medium.

Keywords: Zerovalent copper, Pistachio, Biomass, Cr(VI), Adsorption, Kinetics, Synergistic effect.

40

41

42

43

44

45

46

47

48

49

50

51 
53 Consumer demands of expanding population on the planet are met by our industries with production, which is a threat to sustainable development. Herein, industries produce goods as per the demand of the consumer. Industries meet these demands through time-efficient processes, which demand the use of chemicals that could be fossiloriented or mining-oriented (Carvalho 2017). These chemicals then enter into the biosphere through various environmental pathways and food chains (Garvey 2019). Heavy metals are essential components of these chemicals due to their desired redox, coordination, and physical attributes (Aigberua et al. 2018; Vardhan et al. 2019). Chromium is considered as the $7^{\text {th }}$ most abundant element on earth, existing in the core and mantle; and also ranked $21^{\text {st }}$ in the earth crust with an average concentration of $185 \mathrm{mg} \mathrm{kg}^{-1}$ (Sperling 2005). Chromium finds anthropogenic use in leather tanning, manufacturing, electroplating, chemical refining, organic synthesis, etc. (Lunk 2015; Nigam et al. 2015; Tadesse et al. 2017). The majority of the method for the treatment of chromium in wastewater involves the use of chemical precipitation, coagulation, bioreduction, and electrocoagulation, etc. (GracePavithra et al. 2019; Owlad et al. 2009; Peng and Guo 2020; Pradhan et al. 2017). In spite of these treatment techniques, chromium does find its way into our environment, wherein it exists in two oxidation states [i.e. $\mathrm{Cr}(\mathrm{VI})$ and $\mathrm{Cr}$ (III)]. Trivalent chromium is relatively stable and less toxic but poses health concerns at higher concentrations. However, hexavalent chromium is very harmful even at lower concentrations due to its carcinogenicity, hemotoxicity, and genotoxicity (Barceloux and Barceloux 1999; Burrows 2019). Based on the toxicity associated with chromium, the World Health Organization (WHO) (WHO, 2003) and Bureau of Indian Standards (BIS 10500-2012) have set the permissible limit of chromium at $50 \mu \mathrm{g} / \mathrm{L}$ in wastewater.

The treatment of chromium in wastewater by conventional methods like coagulation, electrocoagulation, (Khan et al. 2019; Mahringer et al. 2020; Peng and Guo 2020) and chemical precipitation(Minas et al. 2017) are irreversible processes, wherein extraction of chromium in the desired form may not be feasible from the waste/sludge generated. Apart from this, conventional methods have the drawbacks of being time-consuming, require bulk wastewater, cost, and manpower intensive, poor reproducibility under variable wastewater physicochemical characteristics (Crini and Lichtfouse 2019; Hu et al. 2011; Sharma et al. 2009). More recently there have been studies on various emerging technologies for the treatment of wastewater including ion exchange (Wang et al. 2020), membrane technologies (Namdar et al. 2021), reverse osmosis (Zakmout et al. 2020), bioremediation (He et al. 2020a; Mohamed et al. 2020) phytoremediation (Kullu et al. 2020) etc. Among these techniques, adsorption is a simple and cost-effective technology. Adsorption is based upon the imbalance of intermolecular forces on the surface of solids leading the way to interaction and removal of atoms, ions, or molecules from solution onto the surface of the solid phase (Artioli 2008). Thus, adsorption is a surface phenomenon, requiring more and more active surfaces on the solid phase for efficient adsorption. Various surface-active adsorbents studied for chromium could be classified as lignocellulosic biomass (Çelebi 2020), biochar (Qu et al. 2021), zeolites (He et al. 2020b), Chitosan (Lei et al. 2020), Graphene oxide (Zhang et al. 2020), resin (Vilayatkar et al. 2020), clay (Ashour and Tony 2020), activated charcoal (Mahmudi et al. 2020; Patel 2020) etc. Among lignocellulosic biomass, Picea smithiana cone (Mittal et al. 2016), pistachio 
and/or recovery for $\mathrm{Cr}(\mathrm{VI})$. On the other hand zeolites and activated charcoal show poor surface adsorption for $\mathrm{Cr}(\mathrm{VI})$ oxoanions, due to the characteristic electrostatic surface negative charge (Jorfi et al. 2017; Puszkarewicz and Kaleta 2019; Vaid et al. 2014).

91 Further, new classes of surface-active materials in the form of nanomaterials have shown promising activity. 92 Various nanomaterials studied for $\mathrm{Cr}(\mathrm{VI})$ remediation include nZVI (Sharma et al. 2009), $\mathrm{MnO}_{2}$ (Dinh et al. 2020), $93 \mathrm{ZnO}$ (Le et al. 2019), $\mathrm{TiO}_{2}$ (Gopinath et al. 2020), $\mathrm{Fe}_{2} \mathrm{O}_{3}$ ( $\mathrm{Li}$ et al. 2019), and their variants with other metal/metal oxides and chalcogenides (Karimi-Maleh et al. 2020; Peng and Guo 2020; Zhao et al. 2019). Recently $\mathrm{Cu}_{\mathrm{Cu}} \mathrm{Cu}_{2} \mathrm{O}$ nanoparticles have found application in electrochemical sensing (Devnani et al. 2019; Li et al. 2018) and adsorption of heavy metal (Iqbal et al. 2019). Cu/Fe bimetallic nanocomposite materials have been found suitable for remediation of $\mathrm{Cr}$ (VI) (Jia et al. 2019; Jiang et al. 2018; Qu et al. 2021; Zhu et al. 2016; Zhu et al. 2018), but very few literature reports are known for utilization of zerovalent copper as $\mathrm{Cr}(\mathrm{VI})$ adsorbent (Li et al. 2015a; Wu et al. 2009).

However, CuNPs tend to agglomerate during synthesis and thus the surface area and the activity of the CuNPs is reduced to a large extent (Huang et al. 2012; Li et al. 2015a; Li et al. 2015b). Thus, to prevent agglomeration, stabilizers and immobilizers can be used in-situ during the preparation of the nanoparticles, to ensure dispersion of the nanoparticles. The use of dispersing agents not only provides stable support to the nanoparticles, but also solves the problem pertaining to agglomeration of nanoparticles resulting in pressure drop in the reactor bed and also to the recyclability of nanoparticles (Wu et al., 2009). Supporting materials such as polymers (Saraswathi et al. 2019), zeolites (Xu et al. 2018a), clay (Pandey and Saini 2019), graphene (Xu et al. 2018b), etc. has been widely utilized for the synthesis of adhered nanoparticle scaffolds. Immobilizers have the added advantage of easy separation of the material from the water/wastewater system. The selection of material to be used as an immobilizer becomes very important. As the material must not themselves act as secondary pollutants after they have been employed for the removal of primary pollutants. Many reports support the use of agricultural byproducts and wastes for the removal of heavy metals from wastewater. These biodegradable adsorbent materials are significant in terms of their low cost, abundant availability, easy disposal and use as green adsorbent without pre-treatments with chemicals (Afroze and Sen 2018). Therefore, the use of biodegradable materials as immobilizers becomes very important for this field of application (Guerra et al. 2018). Earlier one of the authors (Sharma et al. 2018; Sharma et al. 2015) has reported the role of cellulose as an immobilizer and in nZVI reductive regenerative for enhanced adsorption of chromium. Thus, lignocellulosic materials can stabilize metal nanoparticles and enhance the adsorption of $\mathrm{Cr}(\mathrm{VI})$. Therefore, this study attempted to use pistachio shell powder, a biodegradable material known for its $\mathrm{Cr}(\mathrm{VI})$ removal tendencies (Banerjee et al. 2018) as support for the synthesis of zero-valent copper nanoparticle dispersed nanocomposite material using appropriate chemical reduction methods and investigate the synergistic effect of these two adsorbents for their $\mathrm{Cr}(\mathrm{VI})$ removal efficacies.

\section{2. Materials and Methods}




\subsection{Preparation of pistachio shell (PS) powder}

123 Waste pistachio shells used for the studies were collected from the local market. The pistachio shells were washed 124 twice with distilled water before subjecting to air drying in an electric oven for the duration of $24 \mathrm{~h}$ at $100{ }^{\circ} \mathrm{C}$ 125 temperature. The dried shells were grounded using a common household grinder (Bajaj GX1) and sieved to get a 126 homogenous mesh of opening size $250-350 \mu \mathrm{m}$.

\subsection{Reagents and material}

The chemical reagents used for the studies including $\mathrm{CuSO}_{4} .5 \mathrm{H}_{2} \mathrm{O}, \mathrm{NaBH}_{4}, \mathrm{~K}_{2} \mathrm{Cr}_{2} \mathrm{O}_{7}$, diphenylcarbazide were analytical reagent grade and purchased from Loba Chemie Laboratory Reagents, India. All reagents were prepared in deionized water. Diphenylcarbazide was used for the determination of $\mathrm{Cr}(\mathrm{VI})$ concentrations (Lace et al. 2019).

\subsection{Preparation of ZVC@PS composite}

Pistachio shell powder $(4.0 \mathrm{~g})$ was suspended in $100 \mathrm{~mL}$ of distilled water at room temperature. $\mathrm{CuSO}_{4} .5 \mathrm{H}_{2} \mathrm{O}(0.17$ mol, $4.4 \mathrm{~g}$ ) solution in $50 \mathrm{~mL}$ water was added to the reaction mixture with vigorous stirring. To this solution was added dropwise a $20 \%$ aqueous $\mathrm{NaBH}_{4}$ solution $(100 \mathrm{~mL})$ at a constant rate of $1 \mathrm{~mL} / \mathrm{min}$. After the completion of the addition, the reaction mixture turned black and was subjected to stirring at room temperature for $30 \mathrm{~min}$. The black material was filtered, washed with an excess amount of distilled water followed by methanol, and dried under inert conditions in vacuo.

\subsection{Physical Characterization of ZVC@PS}

FTIR analysis (Bruker, Model: Tensor 27) was performed to determine the characteristic bonds in ZVC@PS. X-ray powder diffraction analysis (Bruker, Model: D8-Advance) was performed to evaluate the crystal structure and crystal phase of the ZVC@PS composite at $2 \theta$ angles ranging from $5^{\circ}$ to $80^{\circ}$ with a scanning rate of $3^{\circ}(2 \theta)$ per minute at an accelerating voltage of $40 \mathrm{kV}$ and emission current of $40 \mathrm{~mA}$. The surface morphologies of the ZVC@PS and pistachio shell powder were characterized by field emission scanning electron microscopy (FESEM, Carl Zeiss, Model: Merlin Compact, Germany) with integrated energy dispersive X-ray (EDX) analyzer system. Xray Photo-electron spectroscopy (XPS, Physical Electronics, Model: PHI 5000 VersaProbe III, USA) was used to determine the main element composition and valence state changes of the ZVC@PS composite. Pistachio shell powder and ZVC@PS specific surface area were investigated in BET (Micromeritics, Model: ASAP 2010, France) at $-196{ }^{\circ} \mathrm{C}$. Adsorbent degassing was performed under a nitrogen environment at $150{ }^{\circ} \mathrm{C}$ temperature for $4 \mathrm{~h}$.

149 Thermogravimetric measurements were performed using Thermogravimetric/Differential Thermal Analyzer 150 (EXSTAR SII 6300, LabX, Canada) at a heating rate of $10{ }^{\circ} \mathrm{C} / \mathrm{min}$. UV-vis spectrophotometer (Shimadzu Japan, 151 Model: UV-2450) was used for determination of $\mathrm{Cr}(\mathrm{VI})$ concentration using diphenylcarbazide method.

\subsection{Experimental}




\subsubsection{Adsorption Equilibrium Study}

A stock solution $(1.0 \mathrm{mM})$ of $\mathrm{K}_{2} \mathrm{Cr}_{2} \mathrm{O}_{7}(294.0 \mathrm{mg})$ was prepared by dissolving it into deionized water (1000 $\left.\mathrm{mL}\right)$ and standard $\mathrm{Cr}(\mathrm{VI})$ concentrations of $2-20 \mathrm{mg} / \mathrm{L}$ obtained by serial dilution of the stock solution with deionized water, were used for the adsorption study. ZVC@PS (100 mg/L) was added to individual Erlenmeyer flasks containing $100 \mathrm{~mL}$ solutions of $\mathrm{Cr}(\mathrm{VI})(2-20 \mathrm{mg} / \mathrm{L})$, and the resulting mixtures were incubated at $25 \pm 2{ }^{\circ} \mathrm{C}$ and $180 \mathrm{rpm}$ for 24 h. The samples were subjected to filtration using Whatman 1 filter paper and analyzed for $\mathrm{Cr}(\mathrm{VI})$ concentration via diphenylcarbazide method using UV-Vis spectrophotometer at a wavelength of $540 \mathrm{~nm}$ (Lace, Ryan et al. 2019). The absorption efficiency (i.e. \% Cr removal) and equilibrium adsorption capacity, $\mathrm{q}_{\mathrm{e}}\left(\mathrm{mg}_{\mathrm{Cr}(\mathrm{VI})} / \mathrm{g}_{\mathbf{Z V C}} @ \mathbf{P s}\right)$ were calculated using equation (1) and (2).

$$
\operatorname{Cr}(\mathrm{VI}) \text { removal }(\%)=\frac{C_{o}-C_{e}}{C_{o}} \times 100
$$

Where, $C_{o}$ and $C_{e}\left(\mathrm{mg} \cdot \mathrm{L}^{-1}\right)$ are the initial and equilibrium $\mathrm{Cr}(\mathrm{VI})$ concentration in $\mathrm{mg} / \mathrm{L}$, respectively.

$$
\mathrm{q}_{\mathrm{e}}=\frac{\left(C_{o}-C_{e}\right) V}{W}
$$

Where $V$ is the volume of the solution (in L) and $W$ is the mass of adsorbent ZVC@PS taken.

Studies were performed by varying parameters like $\mathrm{pH}$, adsorbent concentration, and initial dichromate concentration to investigate the effect of different experimental parameters on the $\mathrm{Cr}(\mathrm{VI})$ adsorption and under optimized conditions. The Cr(VI) concentration of $20 \mathrm{mg} / \mathrm{L}$ and ZVC@PS dose concentration of $1.0 \mathrm{~g} / \mathrm{L}$ was selected for $\mathrm{pH}$ optimization study. $\mathrm{Cr}(\mathrm{VI})$ solutions $(100 \mathrm{~mL})$ having different $\mathrm{pH}$ ranging from 2 to 10 were prepared by adjusting the $\mathrm{pH}$ with $1 \mathrm{~N} \mathrm{HCl}$ and or $\mathrm{NaOH}$ solutions. The optimum dose determination experiment was performed using $20 \mathrm{mg} / \mathrm{L}$ of $\mathrm{Cr}(\mathrm{VI})$ solution with varying amounts of ZVC@PS $(0.05,0.1,0.15$, and $0.2 \mathrm{~g} / \mathrm{L})$ at optimum $\mathrm{pH}$ 3. All experiments were carried out in duplicate and average results are reported.

\subsubsection{Kinetic and isotherm experiments}

Adsorption of $\mathrm{Cr}(\mathrm{VI})$ using $\mathbf{Z V C} @ \mathbf{P S}$ was analyzed for its kinetics of adsorption and for optimization of equilibration time. The procedure used to perform kinetic experiments was the same for the determination of adsorption efficiency of ZVC@PS. To a $100 \mathrm{~mL}$ solution of $\mathrm{Cr}(\mathrm{VI})$ at a concentration of $20 \mathrm{mg} / \mathrm{L}$ was added $10 \mathrm{mg}$ of ZVC@PS and incubated at $25 \pm 2{ }^{\circ} \mathrm{C}$ and $180 \mathrm{rpm}$ for $24 \mathrm{~h}$. A fixed volume of the reaction mixture was withdrawn and diluted at regular intervals of time i.e. $0.5,1,2,3,4,6,8,10,12$, and $24 \mathrm{hr}$ to analyze the residual $\mathrm{Cr}(\mathrm{VI})$ concentration. The data thus obtained for $\mathrm{Cr}(\mathrm{VI})$ adsorption onto ZVC@PS as a function of time and was plotted to find the suitable fit to kinetic model.

\subsubsection{Adsorption isotherm study}


The adsorption equilibriums were determined using Langmuir and Freundlich isotherms between ZVC@PS and Cr. In Langmuir adsorption isotherm, adsorption is assumed to be independent for each entity of adsorbate with the formation of a monolayer on the surface. Linearized form of the Langmuir equation (3) is:

$$
\frac{1}{q_{e}}=\frac{1}{q_{\max } K_{L} C_{e}}+\frac{1}{q_{\max }}
$$

This model was used to draw a correlation between $\mathrm{q}_{\mathrm{e}}(\mathrm{mg} / \mathrm{g})$ i.e. the amount of $\mathrm{Cr}(\mathrm{VI})$ adsorbed at equilibrium, $\mathrm{C}_{\mathrm{e}}$ $(\mathrm{mg} / \mathrm{L})$ i.e. equilibrium solute concentration, where $\mathrm{q}_{\max }$ is the maximum saturation monolayer adsorption expressed in $\mathrm{mg} / \mathrm{g}$, and $\mathrm{K}_{L}$ is the Langmuir equilibrium constant.

The equilibrium parameter in Langmuir isotherm can be expressed in terms of a dimensionless constant ( $\mathrm{R}_{\mathrm{L}}$, also called separation factor) by equation (4) as follows:

$$
R_{L}=1 /\left(1+K_{L} C_{0}\right)
$$

The value of $R_{L}$ signifies the nature of isotherm i.e. unfavorable for $R_{L}>1$; linear for $R_{L}=1$; favorable for $0<R_{L}$ $<1$; or irreversible for $\mathrm{R}_{\mathrm{L}}=0$.

The Freundlich adsorption isotherm is applied to non-ideal sorption on heterogeneous surfaces as well as multilayer sorption and adsorption capacity is related to the $\mathrm{Cr}(\mathrm{VI})$ concentration at equilibrium. Linear form of Freundlich model is defined by equation (5) as:

$$
\log \mathrm{q}_{\mathrm{e}}=\log \mathrm{K}_{f}+\frac{1}{n} \log \mathrm{C}_{\mathrm{e}}
$$

A straight-line graph is obtained upon plotting $\log q_{e}$ versus $\log C_{e}$ with a slope of $\left(\frac{1}{n}\right)$ and intercept $\log \mathrm{K}_{f}$. The adsorption capacity and adsorption intensity are related to Freundlich constant $\mathrm{K}_{f}$ and $\left(\frac{1}{n}\right)$,respectively.

\subsubsection{Removal Kinetics study}

Adsorption kinetics depends upon various factors such as initial concentration, contact time, and temperature. The $\mathrm{Cr}(\mathrm{VI})$ adsorption kinetic studies are performed with $20 \mathrm{mg} / \mathrm{L}$ of $\mathrm{Cr}(\mathrm{VI})$ aqueous solution and $100 \mathrm{mg} / \mathrm{L}$ of adsorbent ZVC@PS.

The pseudo-first-order and pseudo-second-order kinetic models are used for the investigation of the mechanism of reduction, mass transport, and chemical reaction process involved in adsorption of $\mathrm{Cr}(\mathrm{VI})$ by ZVC@PS.

Linearized form of pseudo-first-order model is as given in eqn (6)

$$
\ln \left(\mathrm{q}_{\mathrm{e}}-\mathrm{q}_{\mathrm{t}}\right)=\ln \mathrm{q}_{\mathrm{e}}-\mathrm{K}_{\mathrm{t}}
$$

where; $\mathrm{q}_{\mathrm{e}}=$ amount of chromium adsorbed at an equilibrium in $(\mathrm{mg} / \mathrm{g})$

$\mathrm{q}_{\mathrm{t}}=$ amount of chromium adsorbed at time $\mathrm{t}$

$\mathrm{K}=$ rate constant

Linearized form of pseudo-second-order is as given in eqn (6):

$$
\frac{t}{q_{t}}=\frac{1}{K_{p} q_{e}^{2}}+\frac{t}{q_{e}}
$$

where, $\mathrm{K}_{p}$ is pseudo-second-order rate constant.

\section{Result and discussion}




\subsection{Characterizations of ZVC@PS}

\subsubsection{XRD Pattern Analysis}

X-ray powder diffraction patterns of ZVC@PS before and after Cr adsorption are shown in Fig. 1. XRD of ZVC@PS contained peaks $(2 \theta)$ at 22.1, 36.5, 43.2, 50.4, 61.3, and 74.1 ${ }^{\circ}$. The peaks $(2 \theta)$ at $43.2,50.4$, and $74.1^{\circ}$ are assigned to characteristic peaks of zerovalent copper (JCPDS 89-2838) (Ismail 2020). Two peaks (20) observed at 36.5 and $61.3^{\circ}$ were ascribed to the presence of $\mathrm{Cu}_{2} \mathrm{O}$ (JCPDS-05-0667) as a minor component along with $\mathrm{Cu}(0)$

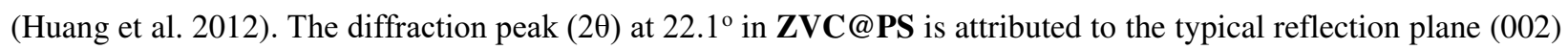
of the lignocellulose framework of pistachio shell powder used as support material (JCPDS card no. 03-0289) (Cottayil et al. 2015). The XRD pattern adsorbent (Cr-ZVC@PS) exhibited the disappearance of peaks characteristic of $\mathrm{Cu}(0)$ nanoparticles at $43.2,50.4$, and $74.1^{\circ}$ upon $\mathrm{Cr}(\mathrm{VI})$ adsorption at $\mathrm{pH}$. This is ascribed to oxidation of $\mathrm{Cu}(0)$ to $\mathrm{Cu}(\mathrm{I}$ or II) during reductive removal of $\mathrm{Cr}(\mathrm{VI})$ to $\mathrm{Cr}$ (III).

\subsubsection{FTIR spectral Analysis}

Fourier Transform Infrared (FTIR) spectral analysis was employed for the determination of characteristic bonds in the lignocellulosic biomass containing pistachio shell powder and immobilized zerovalent copper on pistachio shell powder as a nanocomposite material. The pistachio shell powder with the presence of lignocellulose biomass was characterized by FTIR. The IR of PS showed absorption bands at 3390, 2918, 1632, 1384, 1178, 1161, 1139, 1084, and $877 \mathrm{~cm}^{-1}$ (Fig. 2). The bands that appeared at 1178, 1161, 1084, and $877 \mathrm{~cm}^{-1}$, for the PS, were characteristic of the monomer pyranose ring structure of cellulose. The broad peak at $3390 \mathrm{~cm}^{-1}$ was assigned to $-\mathrm{OH}$ stretching vibrations of primary/secondary -OH groups of the glucopyranose of cellulose or phenolic -OH groups of lignin present as a basic framework of biomass. The peak at $2917 \mathrm{~cm}^{-1}$ is attributed to aliphatic $\mathrm{C}-\mathrm{H}$ stretching, which confirmed the presence of $\mathrm{CH}_{2} / \mathrm{CH}_{3}$ groups, however, the band at $1380 \mathrm{~cm}^{-1}$ is characteristic of the bending of the $\mathrm{C}-\mathrm{H}$ group (Liu et al. 2006). The absorption band at $1632 \mathrm{~cm}^{-1}$ was attributed to the bending mode of the absorbed water. The peaks at 1084 and $877 \mathrm{~cm}^{-1}$, respectively, correspond to the $\mathrm{C}-\mathrm{O}-\mathrm{C}$ group of primary hydroxyl stretching at $\mathrm{C}_{6}$ and $\mathrm{C}_{1}-\mathrm{H}$ group deforming with ring vibration. This confirms the $\beta$-glycosidic linkage (Banerjee et al. 2018). The surface chemical interaction of zerovalent copper with the functional groups of the lignocellulose framework of pistachio biomass was evident from the significant shifts in all absorption peaks. The reductive adsorption of chromium on ZVC@PS changes the chemical nature of ZVC particles on the surface and hence results in its decreased interaction with the functional groups causing the shift of bands towards normal values as appeared in FTIR of pistachio shell powder.

\subsubsection{FESEM and EDX Analysis}

The morphologies of the synthesized ZVC@PS nanocomposite material were analyzed using a field emission scanning electron microscope (FESEM). The pistachio shell powder exhibited undefined morphologies with particle sizes ranging from 10 to $100 \mu \mathrm{m}$ as shown in Fig. 3a. FESEM of zero-valent copper (ZVC) particles (Fig. 3b), synthesized by borohydride reduction, were found primarily in an agglomerated state but well dispersed on the 
surface of the pistachio shell powder. The $\mathrm{Cu}^{0}$ nanoparticles were spherical in shape (Fig. 3c) and were formed with an average size of $40 \mathrm{~nm}$. The SEM-EDX spectrum analysis of PS contains peaks from carbon and oxygen. The EDX spectrum of ZVC@PS exhibits peaks from copper along with carbon and oxygen, with no contamination from any other metal. The adsorption of $\mathrm{Cr}(\mathrm{VI})$ on ZVC@PS was confirmed from the appearance of the characteristic peak of Cr along with other elements (Fig. 3d-f).

\subsubsection{BET Analysis}

Brunauer-Emmett-Teller (BET) analysis of ZVC@PS was performed and compared with PS to determine the surface area and contribution of immobilized nano-zerovalent copper (ZVC) towards the surface area of the material. The specific surface area of PS was found to be $0.483 \mathrm{~m}^{2} / \mathrm{g}$ with an average BJH (Barrett-Joyner-Halenda) pore size distribution of $5.7578 \mathrm{~nm}$ (Turan and Mesci 2011). The relatively lower surface area suggests the microporous nature of the PS. Further, it characterized the poor adsorption capacity of $\mathbf{P S}$ for $\mathrm{Cr}(\mathrm{VI})$ up to $28 \mathrm{mg} / \mathrm{g}$ (Banerjee et al. 2018). On the contrary, the specific surface area of the ZVC@PS was found to be $5.84 \mathrm{~m}^{2} / \mathrm{g}$, which was significantly higher than that of PS. The average BJH pore diameter of ZVC@PS was observed at $911 \mathrm{~nm}$ with the satellite peak at $1374 \mathrm{~nm}$ (Fig. 4b). The substantial increase in specific surface area of ZVC@PS was attributed to additional pores created by immobilized nano zerovalent copper (ZVC) on the surface of PS.

\subsubsection{XPS Analysis}

X-ray photoelectron spectroscopy (XPS) was used to determine the elemental compositions of surfaces of ZVC@PS and Cr(VI) adsorbed ZVC@PS. The XPS survey scan of ZVC@PS and Cr(VI) adsorbed ZVC@PS is depicted in Fig. 5a. Further, the deconvolution of the data was carried out with curve smoothing for $\mathrm{Cu} 2 \mathrm{p}$ and $\mathrm{O} 1 \mathrm{~s}$ to find out the various source and oxidation states of these elements. The analysis of the survey scan of ZVC@PS showed characteristic peaks in the range 529-536, 823, and 930-960 eV, which is characteristic of elements $\mathrm{O}, \mathrm{C}$, and $\mathrm{Cu}$, respectively in the sample surface.

273

The binding energy peaks for $\mathrm{Cu} 2 \mathrm{p}$ of ZVC@PS were observed at 932.1, 934.3, 942.5, and $953.4 \mathrm{eV}$ (Fig. 5b). These peaks were deconvoluted to find the contribution of various $\mathrm{Cu}$ species. The binding energy peak at 932.1 and $953.4 \mathrm{eV}$ suggest the presence of $\mathrm{Cu}(0)$ whereas, the binding energy peak at 934.3 and $942.5 \mathrm{eV}$ are characteristic of $\mathrm{Cu}$ (II) present in ZVC@PS (Chang et al. 2019; Dong et al. 2014; Wu et al. 2009). The analysis of binding energy of $\mathrm{Cu}$ in ZVC@PS indicates the presence of $\mathrm{Cu}$ in $\mathrm{Cu}(0)$, as well as $\mathrm{Cu}(\mathrm{II})$ on the surface, wherein surface- $\mathrm{Cu}(\mathrm{II})$, could be attributed to the chemisorbed impurities of oxygen species. The Fig. 5d is the O1s XPS spectrum of ZVC@PS that has three different peaks at 529.4, 531.1, and $532.4 \mathrm{eV}$, which are attributed to $\mathrm{Cu}(\mathrm{I})$ oxide, oxygen in biomass polymer, and chemisorbed oxygen species like $\mathrm{O}$, $\mathrm{OH}$, etc., respectively (Wang et al. 2015).

The $\mathrm{Cr}(\mathrm{VI})$ adsorbed ZVC@PS showed peaks at 529-534, 570-590, 823, and 930-960 eV, are characteristic of elements $\mathrm{O}, \mathrm{Cr}, \mathrm{C}$, and $\mathrm{Cu}$, respectively. Upon deconvolution of $\mathrm{O} 1 \mathrm{~s}$ spectral peak from $529-534 \mathrm{eV}$, showed the presence of only two species in the sample characterized by the peak at 529.5 and $531.4 \mathrm{eV}$. The O1s peak at 532.4 is attributed to the $\mathrm{C}=\mathrm{O}, \mathrm{C}-\mathrm{O}$, of biomass as well as the $\mathrm{Cu}_{2} \mathrm{O}$ due to sorption of $\mathrm{Cr}(\mathrm{VI})$. The characteristic 
deconvoluted peak corresponding to O1s at $534.4 \mathrm{eV}$ in ZVC@PS was missing in the $\mathrm{Cr}(\mathrm{VI})$ adsorbed sample and could be attributed to the displacement of chemisorbed oxygen by the incoming $\mathrm{Cr}$ (III/VI) species on the surface of ZVC. The weak $\mathrm{Cr} 2 \mathrm{p}_{3 / 2}$ and $\mathrm{Cr} 2 \mathrm{p}_{1 / 2}$ binding energy peaks observed at 574 and $585 \mathrm{eV}$, respectively, were characteristic of $\mathrm{Cr}(\mathrm{III})$ oxide and $\mathrm{Cr}(\mathrm{OH})_{3}$. Thus indicating reduction of $\mathrm{Cr}(\mathrm{VI})$ to $\mathrm{Cr}(\mathrm{III})$ under the adsorption conditions using ZVC@PS as adsorbent. The binding energy peak of $\mathrm{Cu}$ in $\mathrm{Cr}(\mathrm{VI})$ adsorbed ZVC@PS showed four deconvoluted peaks at 931, 933, 942.2, and $951.8 \mathrm{eV}$. The presence of $\mathrm{CuO}$ in $\mathrm{Cr}(\mathrm{VI})$ adsorbed ZVC@PS was characterized by the $\mathrm{Cu} 2 \mathrm{p}_{3 / 2}$ and $\mathrm{Cu} 2 \mathrm{p}_{1 / 2}$ at 933.6 and $951.8 \mathrm{eV}$, respectively (Chang et al. 2019; Ji et al. 2018; Park et al. 2006; Wang et al. 2015). The $\mathrm{Cu} 2 \mathrm{p}$ peaks after $\mathrm{Cr}(\mathrm{VI})$ adsorption showed a shift to lower binding energies as it was attributed to the lower concentration of $\mathrm{Cu}(\mathrm{II})$ species after $\mathrm{Cr}(\mathrm{VI})$ adsorption.

\subsubsection{TGA Analysis}

Thermal stabilities of pistachio shell powder (PS), zerovalent copper loaded pistachio shell powder nanocomposite before (ZVC@PS) and after chromium adsorption (ZVC@PS-Cr) were studied by TGA and DTA techniques. In Fig. 6a, the PS decomposed completely in TGA analysis, as it consists of only organic matters. The TGA curve of ZVC@PS showed mass loss up to $60 \%$ at the temperature $410{ }^{\circ} \mathrm{C}$ and retained the remaining mass up to 600 ${ }^{\circ} \mathrm{C}$. The TGA curve of ZVC@PS after Cr adsorption showed higher mass loss up to $80 \%$ till $410{ }^{\circ} \mathrm{C}$ and no further mass loss observed till $600{ }^{\circ} \mathrm{C}$. This trend of TGA curves indicates the presence of non-oxidizable inorganic substances in ZVC@PS and ZVC@PS-Cr materials that did not decompose till $600{ }^{\circ} \mathrm{C}$. The DTA curves of PS, ZVC@PS, and ZVC@PS-Cr are shown in Fig. 6b. All three materials exhibited thermal degradation in two stages. The first stage or primary decomposition having a temperature range from $220-320{ }^{\circ} \mathrm{C}$ involves the weight loss of $65 \%$ with degradation of glycosyl units of hemicellulose and cellulose accompanied by the evolution of gases like $\mathrm{CO}, \mathrm{CO}_{2}, \mathrm{H}_{2} \mathrm{O}$, etc. along with the formation of levoglucosan and charred residues (Shafizadeh 1982). The second stage or secondary decomposition with a temperature range from $340-500{ }^{\circ} \mathrm{C}$ was assigned to degradation of levoglucosan, decomposition of high energy bonds of lignin, and burning of char, resulting in loss of $30 \%$ of total weight (Cheng et al. 2012). In ZVC@PS the thermal decomposition was observed in the temperature range of 200$290{ }^{\circ} \mathrm{C}$ in the first stage and $310-400{ }^{\circ} \mathrm{C}$ in the second stage. The shift in the degradation curve towards the lower temperature in ZVC@PS indicated the copper-mediated internal oxidative combustion of lignocellulosic biomass resulting in its lower thermal stability in comparison to PS. There was no significant change observed in the decomposition curve up to $600{ }^{\circ} \mathrm{C}$, which indicates the complete oxidation of $\mathrm{Cu}(0)$ to $\mathrm{Cu}(\mathrm{II})$. The TG curve of the chromium adsorbed sample exhibited a shift towards higher temperature in comparison to ZVC@PS, but with a narrow decomposition temperature range between $270-300{ }^{\circ} \mathrm{C}$ in the first stage and $310-370{ }^{\circ} \mathrm{C}$ in the second stage. The residual content was significantly higher than PS in before and after $\mathrm{Cr}(\mathrm{VI})$ adsorption samples of ZVC@PS, which accounted for oxidation of copper and adsorption of $\mathrm{Cr}(\mathrm{VI})$.

The two thermal decomposition peaks at $320^{\circ} \mathrm{C}$ and $480{ }^{\circ} \mathrm{C}$ were observed in the first derivative (DTA) curve of PS pyrolysis. The two decomposition peaks were ascribed to the loss of two structural components of the lignocellulose framework i.e. primary decomposition of relatively simpler cellulose structure and secondary decomposition of 
highly complex lignin structure with high-energy bonds. In the case of copper-loaded ZVC@PS, two endothermic peaks were observed at 285 and $380{ }^{\circ} \mathrm{C}$, with significant lower temperature shifts of $35 \mathrm{~K}$ and $100 \mathrm{~K}$, in the primary and secondary decomposition curves, respectively in comparison to PS. The agglomeration of copper on the surface of PS prevents the oxidation of cellulose and results in more heat gain in ZVC@PS. Further, the narrowing of heat gain peaks in the case of ZVC@PS suggested the heat mediated conversion of copper to its oxide resulted in heat loss, which reinforced the overall degradation process. However, in $\mathrm{Cr}(\mathrm{VI})$ adsorbed samples, the presence of oxides of copper and chromium further prevents cellulose oxidation and results in a high-intensity endothermic peak with a slight shift $(15 \mathrm{~K})$ of the primary decomposition curve towards the higher temperature in comparison to ZVC@PS.

\subsection{Adsorption Studies}

\subsubsection{Effect of pH on Cr(VI) adsorption}

330 The $\mathrm{pH}$ of a solution plays a regulatory role in the adsorption of oxoanion like $\mathrm{Cr}(\mathrm{VI})$. Therefore, the $\mathrm{pH}$ of the solution was optimized for the adsorption of $\mathrm{Cr}(\mathrm{VI})$ onto ZVC@PC. The adsorption studies were performed in varying $\mathrm{pH}$ conditions from 2 to 10 with ZVC@PS dose of $100 \mathrm{mg} / \mathrm{L}$ and $\mathrm{Cr}(\mathrm{VI})$ concentration of $20 \mathrm{mg} / \mathrm{L}$. As the pH increased from 2 to 10 , the $\mathrm{Cr}(\mathrm{VI})$ uptake efficiency of ZVC@PC was decreased from $100 \mathrm{mg} / \mathrm{g}$ to $10 \mathrm{mg} / \mathrm{g}$ (Fig. 7). The adsorption under pH 2 and 3 showed similar results, however, under highly acidic conditions of pH 2, the solution turned yellowish due to dissolution of the oxidized $\mathrm{Cu}$ into the solution. Dissolution of $\mathrm{Cu}(\mathrm{I} / \mathrm{II})$ from ZVC@PS was restricted upon increasing the $\mathrm{pH}$ to 3 and above. The higher removal efficiency for $\mathrm{Cr}(\mathrm{VI})$ at lower pH conditions is ascribed to: (a) surface protonation of ZVC@PS resulting in positively charged surface favoring attractive interaction with $\mathrm{Cr}(\mathrm{VI})$ oxoanion; (b) protonation of $\mathrm{Cr}(\mathrm{VI})$ to reduce electrostatic repulsions with the surface of ZVC@PS and thus facilitates the overall reductive removal of $\mathrm{Cr}(\mathrm{VI})$ ions. At higher $\mathrm{pH}$, the proton concentration is diminished and the negative charge on $\mathrm{Cr}(\mathrm{VI})$ is electrostatically less favored for adsorption on the ZVC@PS surface.

\subsubsection{Effect of ZVC@PS dose on Cr(VI) adsorption}

Effect of adsorbent dose of ZVC@PS was investigated by changing the adsorbent dose from 50 to $200 \mathrm{mg} / \mathrm{L}$ with a $20 \mathrm{mg} / \mathrm{L} \mathrm{Cr}(\mathrm{VI})$ solution maintained at $\mathrm{pH}$ 3. As the adsorbent dose of ZVC@PC increased from 50 to $200 \mathrm{mg} / \mathrm{L}$, the removal of $\mathrm{Cr}(\mathrm{VI})$ increased from 20 to $70 \%$ (Fig. 8). This may account for the increase in the number of available adsorption sites on the nanocomposite adsorbent with the increase in adsorbent dose, resulting in the significant adsorptive removal of $\mathrm{Cr}(\mathrm{VI})$ from the solution. As the dose of the adsorbent was increased from the $\mathrm{Cr}(\mathrm{VI})$ adsorption $\left(\mathrm{q}_{\mathrm{e}}\right)$ decreased from $73.22 \mathrm{mg} / \mathrm{g}$ to $58.13 \mathrm{mg} / \mathrm{g}$. There was a marginal change in $\mathrm{q}_{\mathrm{e}}$ from $100 \mathrm{mg} / \mathrm{L}$ to $150 \mathrm{mg} / \mathrm{g}$ followed by a decrease in adsorption at $200 \mathrm{mg} / \mathrm{g}$. dose of adsorbent can be attributed to the decrease in the number of $\mathrm{Cr}(\mathrm{VI})$ ions available per unit mass of the adsorbent at higher adsorbent dose. Consequently, the active sites on the adsorbent surface remained unsaturated in higher doses. Thus for the optimized conditions used

352 for further study is the adsorbent dose of $100 \mathrm{mg} / \mathrm{L}$. 

uptake increased from 9.42 to $99.3 \mathrm{mg} / \mathrm{g}$, upon increasing the concentration of an aqueous solution from 1 to 20 $\mathrm{mg} / \mathrm{L}$. However, the percentage removal decreased from $100 \%$ to $53.17 \%$ upon increasing the initial concentration of $\mathrm{Cr}(\mathrm{VI})$. These results could be attributed to the increase in the number of $\mathrm{Cr}(\mathrm{VI})$ competing for the same amount of absorbent under increased initial concentration (Fig. 9).

The equilibrium data fitted to both Langmuir and Freundlich adsorption isotherm models and it confirmed the monolayer adsorption behavior of ZVC@PS for $\mathrm{Cr}(\mathrm{VI})$ adsorption from aqueous solution (Fig. 10). The value of $\mathrm{q}_{\max }$, adsorption energy $\left(\mathrm{K}_{\mathrm{L}}\right)$, and dimensionless factor $\mathrm{R}_{\mathrm{L}}$ determined from a linear fit diagram of Langmuir adsorption isotherm models were $111.11 \mathrm{mg} / \mathrm{g} 1.5 \mathrm{~L} / \mathrm{mg}$, and 0.667 , respectively (Table 1). As the value of $\mathrm{R}_{\mathrm{L}}$ lies between 0 and 1, indicates favorable adsorption of Cr(VI) on ZVC@PS.

\subsection{Kinetic equilibrium study}

The rate of $\mathrm{Cr}(\mathrm{VI})$ adsorption was slow with the removal of $77.50 \%$ of $\mathrm{Cr}(\mathrm{VI})$ during the first 120 minutes. The $\mathrm{Cr}(\mathrm{VI})$ adsorption further increased from $77.50 \%$ up to $93.50 \%$ in $17 \mathrm{hrs}$. The initial increase in the adsorption could be attributed to the free availability of adsorption sites on the surface of the adsorbent. Further, the slow kinetics could be attributed to the diffusion of the anion to the surface of the ZVC@PS in the pores.

Lagergren pseudo-first-order and pseudo-second-order adsorption kinetic models were applied to the data. The linear fit diagram of pseudo-first order and pseudo-second-order adsorption kinetic plot are presented in Fig. 11a-b. The kinetic plot shows a poor fit to pseudo-first-order kinetics with $\mathrm{R}^{2}$ equal to 0.805 , whereas a good fit with pseudo-second-order kinetics with $\mathrm{R}^{2}$ equal to 0.989 further verified with a significant chi-square value at a $95 \%$ confidence level. The $\mathrm{q}_{\max }$ and $\mathrm{K}_{\mathrm{t}}$ for the adsorption under pseudo-second-order kinetic fit is $83.3 \mathrm{mg} / \mathrm{g}$ and $1.618 \times$ $37410^{-3} \mathrm{~min}^{-1}$.

\section{4. Discussion}

376 The adsorption experiments showed that the $\mathrm{Cr}(\mathrm{VI})$ adsorption capacity $(111.1 \mathrm{mg} / \mathrm{g})$ of nano zerovalent copper immobilized on to pistachio shell powder (ZVC@PS) was significantly higher than pistachio shell powder (27.95 $\mathrm{mg} / \mathrm{g}$ ) (Banerjee et al. 2018), polymer foam (PEI-PAA) immobilized zero-valent copper $(3.77 \mathrm{mg} / \mathrm{g}$ ) (Li et al. 2015a) and immobilized zerovalent $\mathrm{Fe}(0)(50 \mathrm{mg} / \mathrm{g})$ used for the treatment of $\mathrm{Cr}(\mathrm{VI})$ from wastewater(Shi et al. 2011) (Table 2). This higher Cr(VI) adsorption efficiency of ZVC@PS may be ascribed to the formation of welldispersed ZVC nanoparticles on the surface of pistachio shell powder during synthesis, which otherwise gets agglomerated in the absence of support. A synergistic effect was observed between the $\mathrm{Cr}(\mathrm{VI})$ adsorption tendency of pistachio shell powder and reductive removal of $\mathrm{Cr}(\mathrm{VI})$ by zero-valent copper, which causes a significant increase in $\mathrm{Cr}(\mathrm{VI})$ removal efficiencies of ZVC@PS. The optimum pH for the $\mathrm{Cr}(\mathrm{VI})$ adsorption studies with ZVC@PS was in the acidic conditions, thus favoring its attractive interaction with $\mathrm{Cr}(\mathrm{VI})$ oxoanion. The removal of $\mathrm{Cr}(\mathrm{VI})$ was 
387 in the nanocomposite. Langmuir and Freundlich adsorption isotherm models confirmed the monolayer adsorption behavior of ZVC@PS for Cr(VI).ZVC@PS nanocomposite followed pseudo-second-order kinetic for the $\operatorname{Cr}(\mathrm{VI})$ adsorption with a significant $\mathrm{R}^{2}$ value of 0.989 .

\section{Conclusion}

$391 \quad$ ZVC@PS an eco-efficient nanocomposite was synthesized, characterized, and used for the removal of $\operatorname{Cr}(\mathrm{VI})$ from 392 aqueous solution. Batch experiment studies demonstrated that $\mathrm{Cr}(\mathrm{VI})$ removal rate was increased with a decrease in $393 \mathrm{pH}$ and initial $\mathrm{Cr}(\mathrm{VI})$ concentration, and increase in ZVC@PS dose. At optimum conditions, the $\operatorname{Cr}(\mathrm{VI})$ removal 394 capacity of ZVC@PS is observed as $111.1 \mathrm{mg} / \mathrm{g}$, and the normalized adsorption efficiency of $\mathrm{Cu}$ for $\mathrm{Cr}(\mathrm{VI})$ in 395 ZVC@PS is $284.84 \mathrm{mg} / \mathrm{g}$, which is quite significant. The mechanism of removal of Cr(VI) by ZVC@PS was 396 investigated as surface adsorption with concomitant reduction of $\mathrm{Cr}(\mathrm{VI})$ to $\mathrm{Cr}(\mathrm{III})$. In conclusion, the pistachio shell 397 powder immobilized zerovalent copper could be an efficient and promising material for $\mathrm{Cr}(\mathrm{VI})$ remediation from an aqueous medium.

\section{Abbreviations}

401

PS: pistachio shell; ZVC: zerovalent copper; SEM: scanning electron microscopy; EDX: Energy Dispersive X-rays; FTIR: Fourier-transform infrared; XRD: X-ray powder diffraction; TGA: thermo-gravimetric analysis; DTA: differential thermal analysis; BET: Brunauer-Emmett-Teller; BJH: Barrett-Joyner-Halenda; XPS: X-ray photoelectron spectroscopy.

\section{Declarations}

Ethics approval and consent to participate: Not applicable.

Consent for publication: All the data used for writing this manuscript has been cited with proper references.

Availability of data and materials: Data supporting the results are available in manuscript and can be supplied by the corresponding author on reasonable request.

411 Competing interests: The authors have no competing interests.

412 Funding: Not applicable

413

Authors' contributions: All authors had made equal contribution in collecting data, helping shape the manuscript and providing the critical feedback. 
Sandeep Kumar: The corresponding author of this manuscript contributed via design and supervision of this work, data analysis and interpretation, wrote the manuscript with input from all authors.

Ravinderdeep Singh Brar: The author is research scholar in Department of Chemistry, Akal University and contributed via synthesis of nanocomposite material, and experimental data collection for the manuscript.

\section{Authors' information (optional)}

J Nagendra Babu: The author of this manuscript contributed via supervision of this work, data analysis and interpretation, providing critical feedback, discussion and writing this manuscript.

Amarjeet Dahiya: The author is research scholar in Department of Chemistry, Central University of Punjab and helped in experimental data collection for the manuscript.

Sandip Saha: The author of this manuscript contributed by data analysis and interpretation, designing the figures, providing critical feedback and helped shape the research writings.

Avneesh Kumar: The author helped in designing the work and providing critical feedback for the research outcomes.

Acknowledgements: The authors of this manuscript are thankful to Akal University for providing financial support and research facilities. We are also thankful to Central Instrumentation Facility, Central University of Punjab for assisting in physico-chemical characterization of the material.

\section{References}

Afroze S, Sen TK (2018) A review on heavy metal ions and dye adsorption from water by agricultural solid waste adsorbents. Water, Air, \& Soil Pollution 229(7):1-50. https://doi.org/10.1007/s11270-018-3869-z

Aigberua A, Tarawou J, Abasi C (2018) Effect of oxidation-reduction fluctuations on metal mobility of speciated metals and arsenic in bottom sediments of middleton river, Bayelsa State, Nigeria. Journal of Applied Sciences and Environmental Management 22(9):1511-1517. https://doi.org/10.4314/jasem.v22i9.25.

Artioli Y (2008) Adsorption. In: Jørgensen SE, Fath BD (eds) Encyclopedia of Ecology. Academic Press, Oxford, p $60-65$

Ashour EA, Tony MA (2020) Eco-friendly removal of hexavalent chromium from aqueous solution using natural clay mineral: activation and modification effects. SN Applied Sciences 2(12):1-13. https://doi.org/10.1007/s42452-020-03873-X 
Banerjee M, Bar N, Basu RK, Das SK (2018) Removal of Cr (VI) from its aqueous solution using green adsorbent pistachio shell: a fixed bed column study and GA-ANN modeling. Water Conservation Science and Engineering 3(1):19-31. https://doi.org/10.1007/s41101-017-0039-x

Barceloux DG, Barceloux D (1999) Chromium. Journal of Toxicology: Clinical Toxicology 37(2):173-194. https://doi.org/10.1081/CLT-100102418

Burrows D (2019) Chromium: metabolism and toxicity. CRC press

Carvalho FP (2017) Mining industry and sustainable development: time for change. Food and Energy Security 6(2):61-77. https://doi.org/10.1002/fes3.109.

Çelebi H (2020) Recovery of detox tea wastes: Usage as a lignocellulosic adsorbent in $\mathrm{cr}^{6+}$ adsorption. Journal of Environmental Chemical Engineering 8(5):104310. https://doi.org/10.1016/j.jece.2020.104310

Chang P-H, Chou T-H, Sahu RS, Shih Y-h (2019) Chemical reduction-aided zerovalent copper nanoparticles for 2, 4-dichlorophenol removal. Applied Nanoscience 9(3):387-395. https://doi.org/10.1007/s13204-018-00945$\underline{8}$

Cheng K, Winter WT, Stipanovic AJ (2012) A modulated-TGA approach to the kinetics of lignocellulosic biomass pyrolysis/combustion. Polymer Degradation and Stability 97(9):1606-1615. https://doi.org/10.1016/j.polymdegradstab.2012.06.027

Cottayil SK, Mohan M, Sivasubramanian G (2015) A simple, efficient and sustainable route to cellulose/cu nanocomposite-evaluation of their antimicrobial and free radical scavenging activities. Journal of Green Science and Technology 2(1):20-26. https://doi.org/10.1166/jgst.2015.1037

Crini G, Lichtfouse E (2019) Advantages and disadvantages of techniques used for wastewater treatment. Environmental Chemistry Letters 17(1):145-155. https://doi.org/10.1007/s10311-018-0785-9

Devnani H, Rashid N, Ingole PP (2019) Copper/Cuprous oxide nanoparticles decorated reduced graphene oxide sheets based platform for bio-electrochemical sensing of dopamine. ChemistrySelect 4(2):633-643. https://doi.org/10.1002/slct.201803233

Dinh V-P, et al. (2020) Chitosan- $\mathrm{MnO}_{2}$ nanocomposite for effective removal of $\mathrm{Cr}(\mathrm{VI})$ from aqueous solution. Chemosphere 257:127147. https://doi.org/10.1016/j.chemosphere.2020.127147

Dong G, Ai Z, Zhang L (2014) Total aerobic destruction of azo contaminants with nanoscale zero-valent copper at neutral pH: Promotion effect of in-situ generated carbon center radicals. Water research 66:22-30. https://doi.org/10.1016/j.watres.2014.08.011

Garvey M (2019) Food pollution: a comprehensive review of chemical and biological sources of food contamination and impact on human health. Nutrire 44(1):1-13. https://doi.org/10.1186/s41110-019-0096-3.

Gopinath KP, Madhav NV, Krishnan A, Malolan R, Rangarajan G (2020) Present applications of titanium dioxide for the photocatalytic removal of pollutants from water: A review. Journal of Environmental Management 270:110906. https://doi.org/10.1016/j.jenvman.2020.110906

GracePavithra K, Jaikumar V, Kumar PS, SundarRajan P (2019) A review on cleaner strategies for chromium industrial wastewater: present research and future perspective. Journal of Cleaner Production 228:580-593. https://doi.org/10.1016/j.jclepro.2019.04.117 
Guerra FD, Attia MF, Whitehead DC, Alexis F (2018) Nanotechnology for environmental remediation: materials and applications. Molecules 23(7):1760. https://dx.doi.org/10.3390\%2Fmolecules23071760

$\mathrm{He} \mathrm{C}$, et al. (2020a) Cleaning chromium pollution in aquatic environments by bioremediation, photocatalytic remediation, electrochemical remediation and coupled remediation systems. Environmental Chemistry Letters 18(3):561-576. https://doi.org/10.1007/s10311-019-00960-3

He PY, Zhang YJ, Chen H, Han ZC, Liu LC (2020b) Low-cost and facile synthesis of geopolymer-zeolite composite membrane for chromium (VI) separation from aqueous solution. Journal of hazardous materials 392:122359. https://doi.org/10.1016/j.jhazmat.2020.122359

$\mathrm{Hu} \mathrm{X}-\mathrm{j}$, et al. (2011) Adsorption of chromium (VI) by ethylenediamine-modified cross-linked magnetic chitosan resin: isotherms, kinetics and thermodynamics. Journal of hazardous materials 185(1):306-314. https://doi.org/10.1016/j.jhazmat.2010.09.034

Huang C-C, Lo S-L, Lien H-L (2012) Zero-valent copper nanoparticles for effective dechlorination of dichloromethane using sodium borohydride as a reductant. Chemical Engineering Journal 203:95-100. https://doi.org/10.1016/j.cej.2012.07.002

Iqbal J, et al. (2019) Synergistic effects of activated carbon and nano-zerovalent copper on the performance of hydroxyapatite-alginate beads for the removal of $\mathrm{As}^{3+}$ from aqueous solution. Journal of Cleaner Production 235:875-886. https://doi.org/10.1016/j.jclepro.2019.06.316

Ismail MIM (2020) Green synthesis and characterizations of copper nanoparticles. Materials Chemistry and Physics 240:122283. https://doi.org/10.1016/j.matchemphys.2019.122283

Ji C, Yin S-N, Sun S, Yang S (2018) An in situ mediator-free route to fabricate $\mathrm{Cu}_{2} \mathrm{O} / \mathrm{g}-\mathrm{C}_{3} \mathrm{~N}_{4}$ type-II heterojunctions for enhanced visible-light photocatalytic $\mathrm{H}_{2}$ generation. Applied Surface Science 434:1224-1231. https://doi.org/10.1016/j.apsusc.2017.11.233

Jia T, Zhang B, Huang L, Wang S, Xu C (2019) Enhanced sequestration of $\mathrm{Cr}(\mathrm{VI})$ by copper doped sulfidated zerovalent iron (SZVI-Cu): Characterization, performance, and mechanisms. Chemical Engineering Journal 366:200-207. https://doi.org/10.1016/j.cej.2019.02.058

Jiang D, et al. (2018) Difunctional chitosan-stabilized $\mathrm{Fe} / \mathrm{Cu}$ bimetallic nanoparticles for removal of hexavalent chromium wastewater. Science of The Total Environment 644:1181-1189. https://doi.org/10.1016/j.scitotenv.2018.06.367

Jorfi S, Ahmadi MJ, Pourfadakari S, Jaafarzadeh N, Soltani RDC, Akbari H (2017) Adsorption of Cr(VI) by natural clinoptilolite zeolite from aqueous solutions: isotherms and kinetics. Polish Journal of Chemical Technology 19(3):106-114. http://dx.doi.org/10.1515/pjct-2017-0056

Karimi-Maleh H, et al. (2020) Recent advances in removal techniques of $\mathrm{Cr}(\mathrm{VI})$ toxic ion from aqueous solution: A comprehensive review. Journal of Molecular Liquids:115062. https://doi.org/10.1016/j.molliq.2020.115062

Khan SU, Islam DT, Farooqi IH, Ayub S, Basheer F (2019) Hexavalent chromium removal in an electrocoagulation column reactor: Process optimization using $\mathrm{CCD}$, adsorption kinetics and $\mathrm{pH}$ modulated sludge formation. Process Safety and Environmental Protection 122:118-130. https://doi.org/10.1016/j.psep.2018.11.024 
Kullu B, Patra DK, Acharya S, Pradhan C, Patra HK (2020) AM fungi mediated bioaccumulation of hexavalent chromium in Brachiaria mutica-a mycorrhizal phytoremediation approach. Chemosphere 258:127337. https://doi.org/10.1016/j.chemosphere.2020.127337

Lace A, Ryan D, Bowkett M, Cleary J (2019) Chromium monitoring in water by colorimetry using optimised 1,5diphenylcarbazide method. International Journal of Environmental Research and Public Health 16(10):1803. https://dx.doi.org/10.3390\%2Fijerph16101803

Le AT, Pung S-Y, Sreekantan S, Matsuda A (2019) Mechanisms of removal of heavy metal ions by ZnO particles. Heliyon 5(4):e01440. https://doi.org/10.1016/j.heliyon.2019.e01440

Lei C, Wang C, Chen W, He M, Huang B (2020) Polyaniline@ magnetic chitosan nanomaterials for highly efficient simultaneous adsorption and in-situ chemical reduction of hexavalent chromium: Removal efficacy and $\begin{array}{llllll}\text { mechanisms. } & \text { Science } & \text { 733:139316. }\end{array}$ https://doi.org/10.1016/j.scitotenv.2020.139316

Li B, et al. (2019) Facile modification of activated carbon with highly dispersed nano-sized $\alpha-\mathrm{Fe}_{2} \mathrm{O}_{3}$ for enhanced removal of hexavalent chromium from aqueous solutions. Chemosphere 224:220-227. https://doi.org/10.1016/j.chemosphere.2019.02.121

Li C, Du Z, Zou W, Li H, Zhang C (2015a) Fabrication of copper coated polymer foam and their application for hexavalent chromium removal. Reactive and Functional Polymers 88:24-30. https://doi.org/10.1016/j.reactfunctpolym.2015.02.001

Li J, et al. (2018) Facile synthesis of $\mathrm{Pd}-\mathrm{Cu} @ \mathrm{Cu}_{2} \mathrm{O} / \mathrm{N}-\mathrm{RGO}$ hybrid and its application for electrochemical detection of tryptophan. Electrochimica Acta 260:526-535. https://doi.org/10.1016/j.electacta.2017.12.125

Li P, Song Y, Wang S, Tao Z, Yu S, Liu Y (2015b) Enhanced decolorization of methyl orange using zero-valent copper nanoparticles under assistance of hydrodynamic cavitation. Ultrasonics sonochemistry 22:132-138. https://doi.org/10.1016/j.ultsonch.2014.05.025

Liu CF, et al. (2006) Physicochemical characterization of cellulose from perennial ryegrass leaves (Lolium perenne). Carbohydrate Research 341(16):2677-2687. https://doi.org/10.1016/j.carres.2006.07.008

Lunk H-J (2015) Discovery, properties and applications of chromium and its compounds. ChemTexts 1(1):6. https://doi.org/10.1007/s40828-015-0007-z

Mahmudi M, et al. (2020) An Alternative Activated Carbon from Agricultural Waste on Chromium Removal. Journal of Ecological Engineering 21(8):1-9. https://doi.org/10.12911/22998993/127431

Mahringer D, Zerelli SS, Dippon U, Ruhl AS (2020) Pilot scale hexavalent chromium removal with reduction, coagulation, filtration and biological iron oxidation. Separation and Purification Technology 253:117478. https://doi.org/10.1016/j.seppur.2020.117478

Minas F, Chandravanshi BS, Leta S (2017) Chemical precipitation method for chromium removal and its recovery from tannery wastewater in Ethiopia. Chemistry International 3(4):291-305. https://doi.org/10.31221/osf.io/m7h5k 
Mittal S, Vaid U, Nabi Najar G, Nagendra Babu J (2016) Removal of hexavalent chromium from aqueous solution: a comparative study of cone biomass of "Picea smithiana" and activated charcoal. Desalination and Water Treatment 57(24):11081-11095. https://doi.org/10.1080/19443994.2015.1038594

Mohamed MS, El-Arabi NI, El-Hussein A, El-Maaty SA, Abdelhadi AA (2020) Reduction of chromium-VI by chromium-resistant Escherichia coli FACU: a prospective bacterium for bioremediation. Folia microbiologica 65(4):687-696. https://doi.org/10.1007/s12223-020-00771-y

Namdar H, Akbari A, Yegani R, Roghani-Mamaqani H (2021) Influence of aspartic acid functionalized graphene oxide presence in polyvinylchloride mixed matrix membranes on chromium removal from aqueous feed containing humic acid. Journal of Environmental Chemical Engineering 9(1):104685. https://doi.org/10.1016/j.jece.2020.104685

Nigam H, et al. (2015) Effect of chromium generated by solid waste of tannery and microbial degradation of chromium to reduce its toxicity: a review. Adv Appl Sci Res 6(3):129-136.

Owlad M, Aroua MK, Daud WAW, Baroutian S (2009) Removal of hexavalent chromium-contaminated water and wastewater: a review. Water, Air, and Soil Pollution 200(1):59-77. https://doi.org/10.1007/s11270-0089893-7

Pandey P, Saini VK (2019) Pillared interlayered clays: sustainable materials for pollution abatement. Environmental Chemistry Letters 17(2):721-727. https://doi.org/10.1007/s10311-018-00826-0

Park J-Y, Jung Y-S, Cho J, Choi W-K (2006) Chemical reaction of sputtered Cu film with PI modified by low energy reactive atomic beam. Applied Surface Science 252(16):5877-5891. https://doi.org/10.1016/j.apsusc.2005.08.019

Patel H (2020) Batch and continuous fixed bed adsorption of heavy metals removal using activated charcoal from neem (Azadirachta indica) leaf powder. Scientific Reports 10(1):1-12. https://doi.org/10.1038/s41598-020$\underline{72583-6}$

Peng H, Guo J (2020) Removal of chromium from wastewater by membrane filtration, chemical precipitation, ion exchange, adsorption electrocoagulation, electrochemical reduction, electrodialysis, electrodeionization, photocatalysis and nanotechnology: a review. Environmental Chemistry Letters:1-14. https://doi.org/10.1007/s10311-020-01058-x

Pradhan D, Sukla LB, Sawyer M, Rahman PK (2017) Recent bioreduction of hexavalent chromium in wastewater treatment: a review. Journal of Industrial and Engineering Chemistry 55:1-20. https://doi.org/10.1016/j.jiec.2017.06.040

Puszkarewicz A, Kaleta J (2019) Chromium (vi) adsorption on modified activated carbons. Applied Sciences 9(17):3549. https://doi.org/10.3390/app9173549

Qu J, et al. (2021) KOH-activated porous biochar with high specific surface area for adsorptive removal of chromium (VI) and naphthalene from water: Affecting factors, mechanisms and reusability exploration. Journal of Hazardous Materials 401:123292. https://doi.org/10.1016/j.jhazmat.2020.123292 
Saraswathi MSSA, Nagendran A, Rana D (2019) Tailored polymer nanocomposite membranes based on carbon, metal oxide and silicon nanomaterials: a review. Journal of Materials Chemistry A 7(15):8723-8745. https://doi.org/10.1039/C8TA11460A

Shafizadeh F (1982) Introduction to pyrolysis of biomass. Journal of Analytical and Applied Pyrolysis 3(4):283-305. https://doi.org/10.1016/0165-2370(82)80017-X

Sharma AK, Devan RS, Arora M, Kumar R, Ma Y-R, Babu JN (2018) Reductive-co-precipitated cellulose immobilized zerovalent iron nanoparticles in ionic liquid/water for $\mathrm{Cr}$ (VI) adsorption. Cellulose 25(9):5259-5275. https://doi.org/10.1007/s10570-018-1932-y

Sharma AK, et al. (2015) In situ reductive regeneration of zerovalent iron nanoparticles immobilized on cellulose for atom efficient $\mathrm{Cr}$ (VI) adsorption. RSC advances 5(109):89441-89446. https://doi.org/10.1039/C5RA19917D

Sharma YC, Srivastava V, Weng CH, Upadhyay SN (2009) Removal of Cr(VI) from wastewater by adsorption on iron nanoparticles. The Canadian Journal of Chemical Engineering 87(6):921-929. https://doi.org/10.1002/cjce.20230

Shi L-n, Zhang X, Chen Z-1 (2011) Removal of Chromium (VI) from wastewater using bentonite-supported nanoscale zero-valent iron. Water Research 45(2):886-892. https://doi.org/10.1016/j.watres.2010.09.025

Sperling M (2005) CHROMIUM. In: Worsfold P, Townshend A, Poole C (eds) Encyclopedia of Analytical Science (Second Edition). Elsevier, Oxford, p 113-126

Tadesse GL, Guya TK, Walabu M (2017) Impacts of tannery effluent on environments and human health: a review article. Advances in Life Science and Technology 54:10.

Turan NG, Mesci B (2011) Use of pistachio shells as an adsorbent for the removal of Zinc(II) ion. CLEAN - Soil, Air, Water 39(5):475-481. https://doi.org/10.1002/clen.201000297

Vaid U, Mittal S, Babu JN (2014) Removal of hexavalent chromium from aqueous solution using biomass derived fly ash from Waste-to-Energy power plant. Desalination and Water Treatment 52(40-42):7845-7855. https://doi.org/10.1080/19443994.2013.833554

Vardhan KH, Kumar PS, Panda RC (2019) A review on heavy metal pollution, toxicity and remedial measures: Current trends and future perspectives. Journal of Molecular Liquids 290:111197. https://doi.org/10.1016/j.molliq.2019.111197

Vilayatkar ND, et al. (2020) Synthesis and characterization of terpolymeric resin for removal of hexavalent chromium. Materials Today: Proceedings 29:776-780. https://doi.org/10.1016/j.matpr.2020.04.676

Wang H, Song X, Zhang H, Tan P, Kong F (2020) Removal of hexavalent chromium in dual-chamber microbial fuel cells separated by different ion-exchange membranes. Journal of hazardous materials 384:121459. https://doi.org/10.1016/j.jhazmat.2019.121459

Wang Y, Lü Y, Zhan W, Xie Z, Kuang Q, Zheng L (2015) Synthesis of porous $\mathrm{Cu}_{2} \mathrm{O} / \mathrm{CuO}$ cages using Cu-based metal-organic frameworks as templates and their gas-sensing properties. Journal of Materials Chemistry A 3(24):12796-12803. https://doi.org/10.1039/C5TA01108F 
Wu S-J, Liou T-H, Mi F-L (2009) Synthesis of zero-valent copper-chitosan nanocomposites and their application for treatment of hexavalent chromium. Bioresource technology 100(19):4348-4353. https://doi.org/10.1016/j.biortech.2009.04.013

Xu D, Lv H, Liu B (2018a) Encapsulation of metal nanoparticle catalysts within mesoporous zeolites and their enhanced catalytic performances: a review. Frontiers in chemistry 6:550. https://doi.org/10.3389/fchem.2018.00550

$\mathrm{Xu} \mathrm{J}$, et al. (2018b) A review of functionalized carbon nanotubes and graphene for heavy metal adsorption from water: Preparation, application, and mechanism. Chemosphere 195:351-364. https://doi.org/10.1016/j.chemosphere.2017.12.061

Zakmout A, Sadi F, Portugal CA, Crespo JG, Velizarov S (2020) Tannery effluent treatment by nanofiltration, reverse osmosis and chitosan modified membranes. Membranes 10(12):378. https://doi.org/10.3390/membranes 10120378

Zhang L, Song F, Wang S, Wang H, Yang W, Li Y (2020) Efficient removal of hexavalent chromium and congo red by graphene oxide/silica nanosheets with multistage pores. Journal of Chemical \& Engineering Data 65(9):4354-4368. https://doi.org/10.1021/acs.jced.0c00006

Zhao W, et al. (2019) Simultaneous removal of tetracycline and Cr(VI) by a novel three-dimensional AgI/BiVO4 p$\mathrm{n}$ junction photocatalyst and insight into the photocatalytic mechanism. Chemical Engineering Journal 369:716-725. https://doi.org/10.1016/j.cej.2019.03.115

Zhu F, Li L, Ma S, Shang Z (2016) Effect factors, kinetics and thermodynamics of remediation in the chromium contaminated soils by nanoscale zero valent $\mathrm{Fe} / \mathrm{Cu}$ bimetallic particles. Chemical Engineering Journal 302:663-669. https://doi.org/10.1016/j.cej.2016.05.072

Zhu F, Ma S, Liu T, Deng X (2018) Green synthesis of nano zero-valent iron/Cu by green tea to remove hexavalent chromium from groundwater. Journal of Cleaner Production 174:184-190. https://doi.org/10.1016/j.jclepro.2017.10.302 
655

656

657

658

659

660

661 
Figures

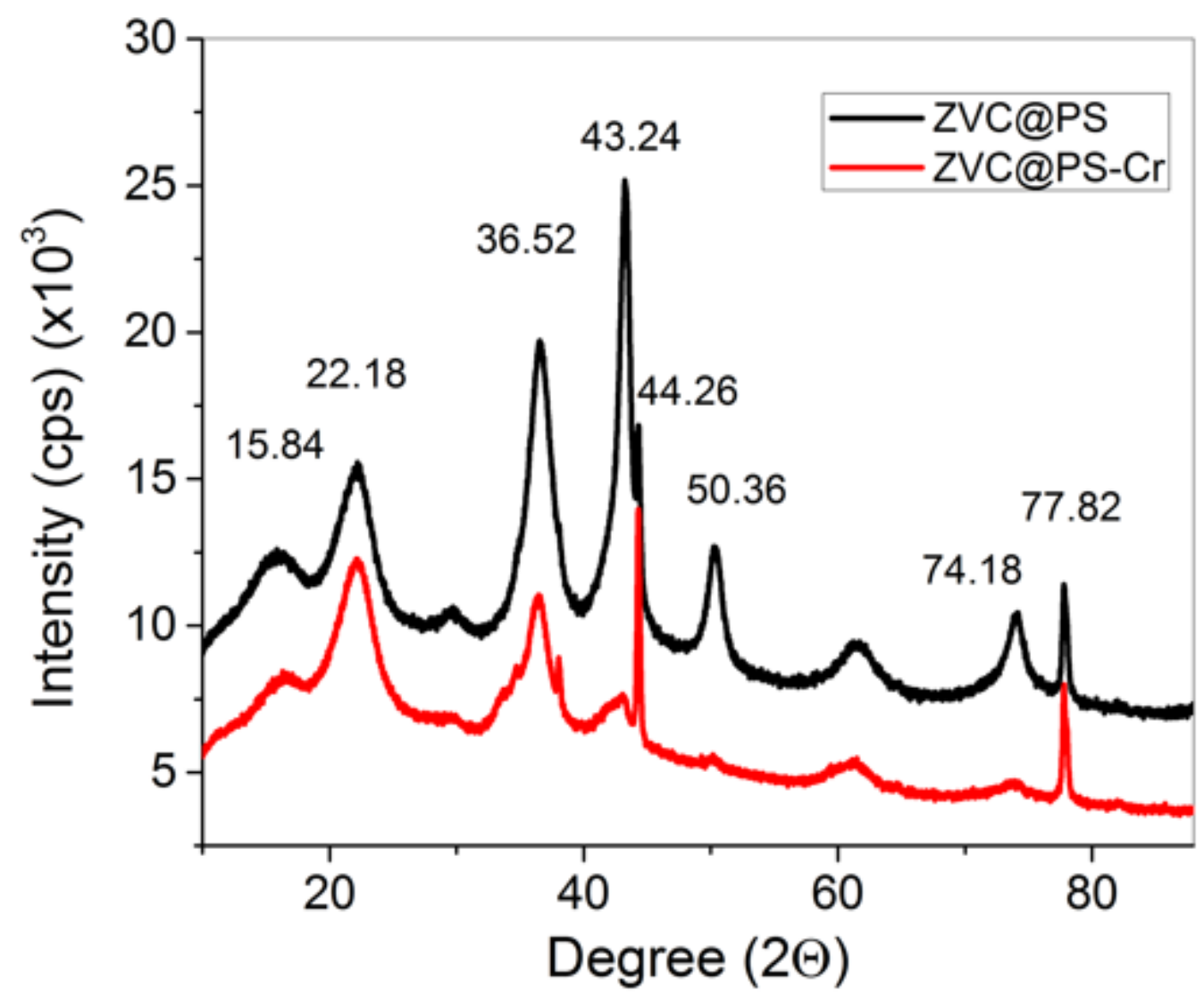

Figure 1

XRD pattern analysis of ZVC@PS and Cr(VI) adsorbed ZVC@PS samples 


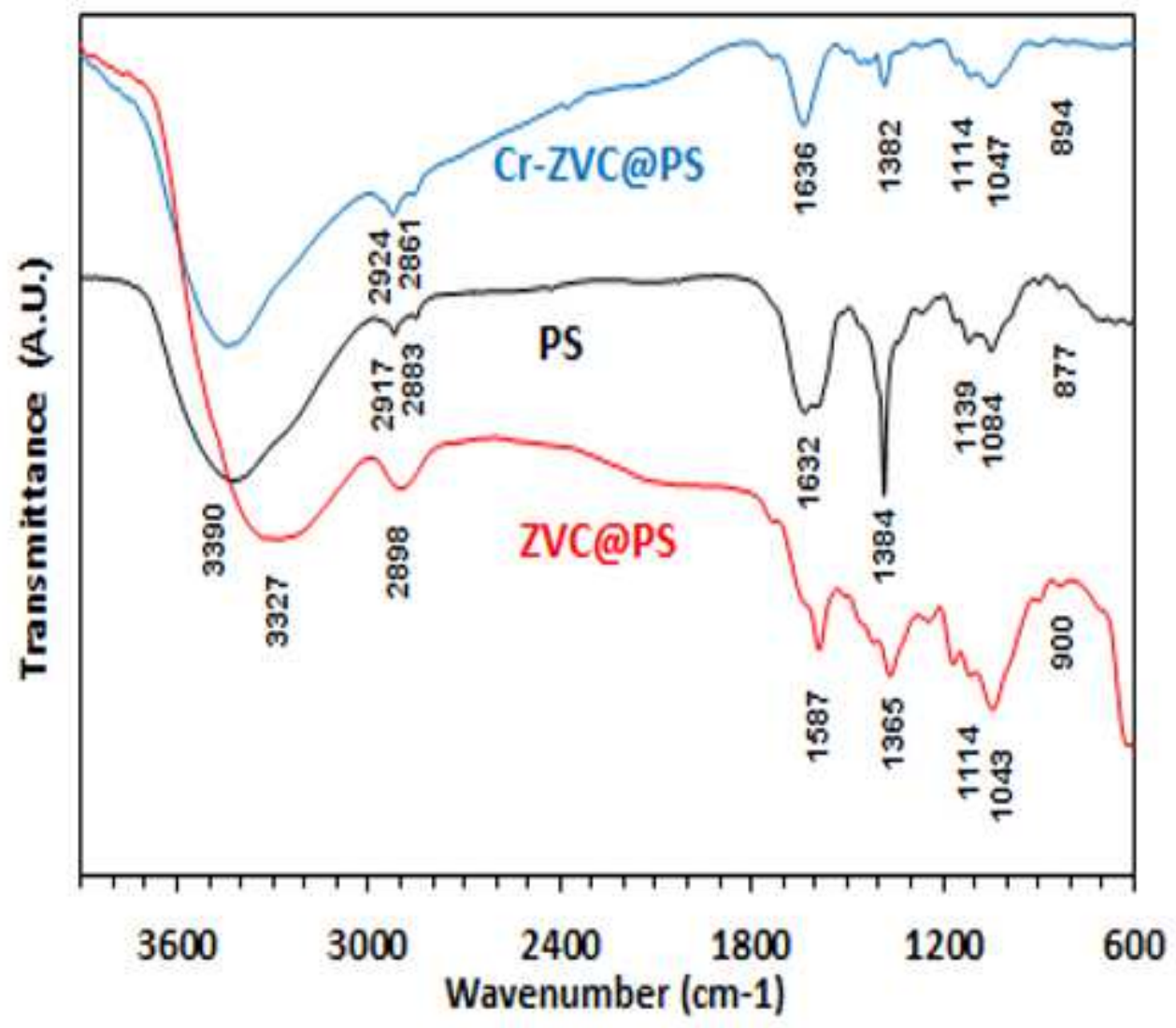

Figure 2

FTIR spectra of PS, ZVC@PS) and Cr(VI) adsorbed ZVC@PS samples
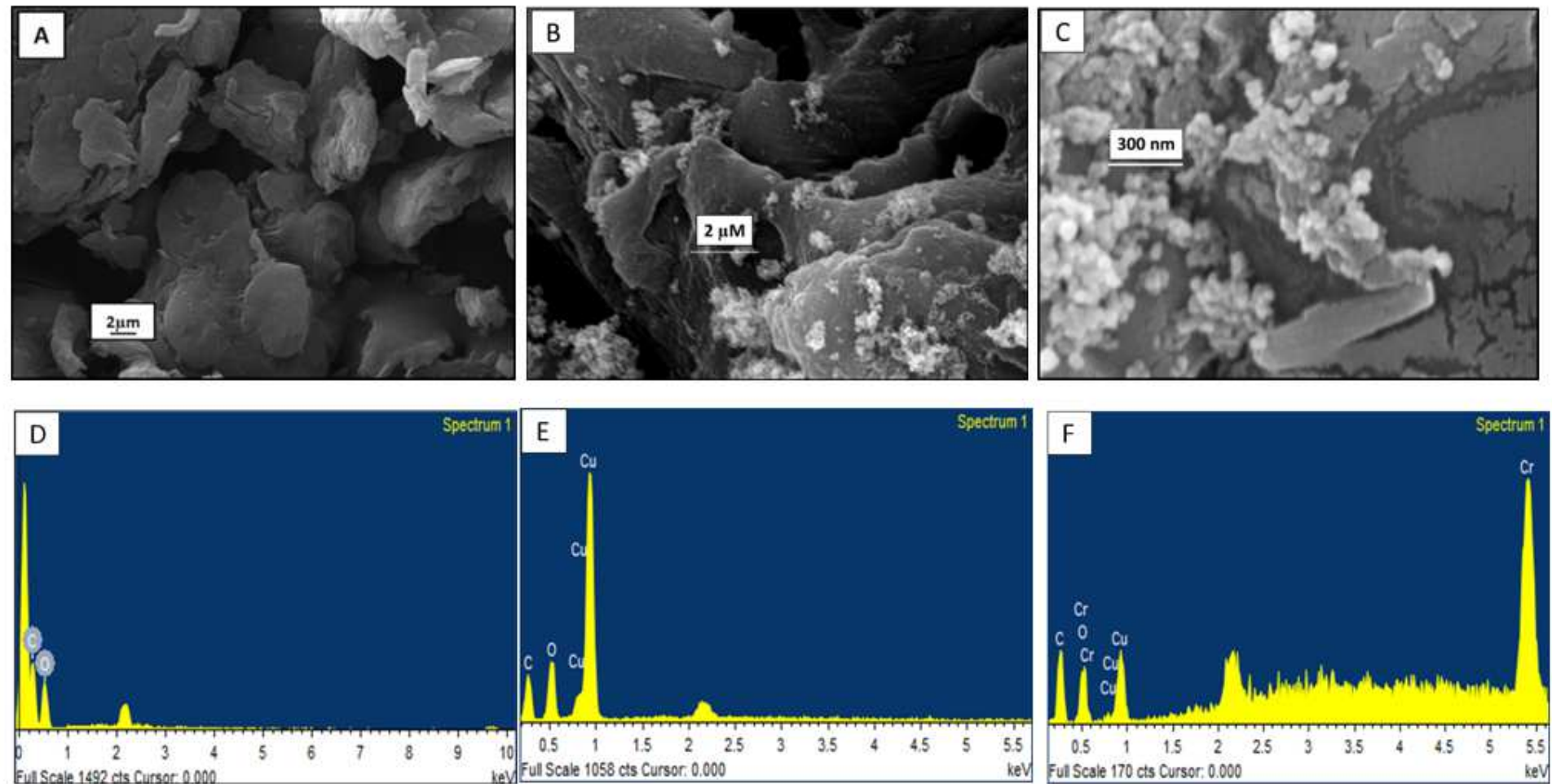
Figure 3

SEM images of (a) PS; (b) ZVC@PS; (c) ZVC@PS at increased magnification. EDX spectra of (d) PS; (e) ZVC@PS; and (f) Cr(VI) adsorbed ZVC@PS
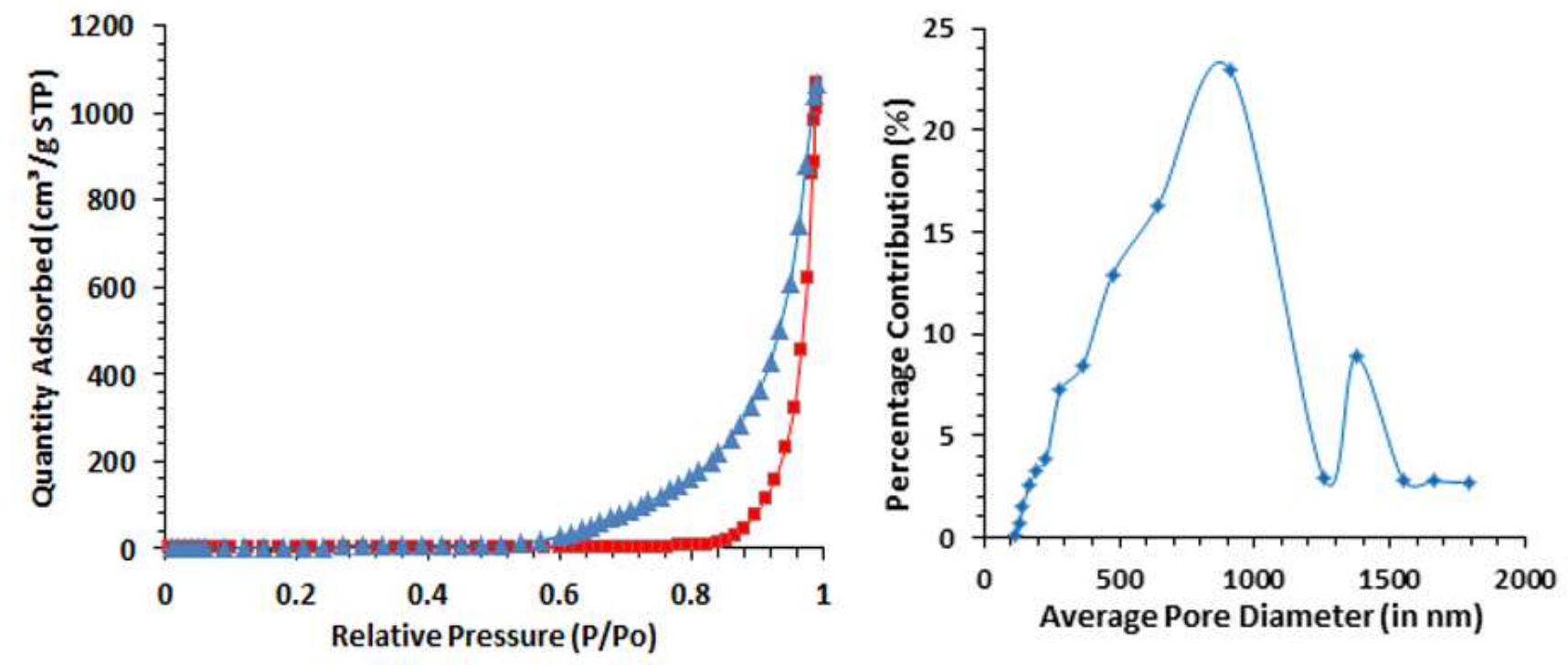

Figure 4

(a) Nitrogen adsorption-desorption isotherm for ZVC@PS; (b) average pore size distribution of ZVC@PS 

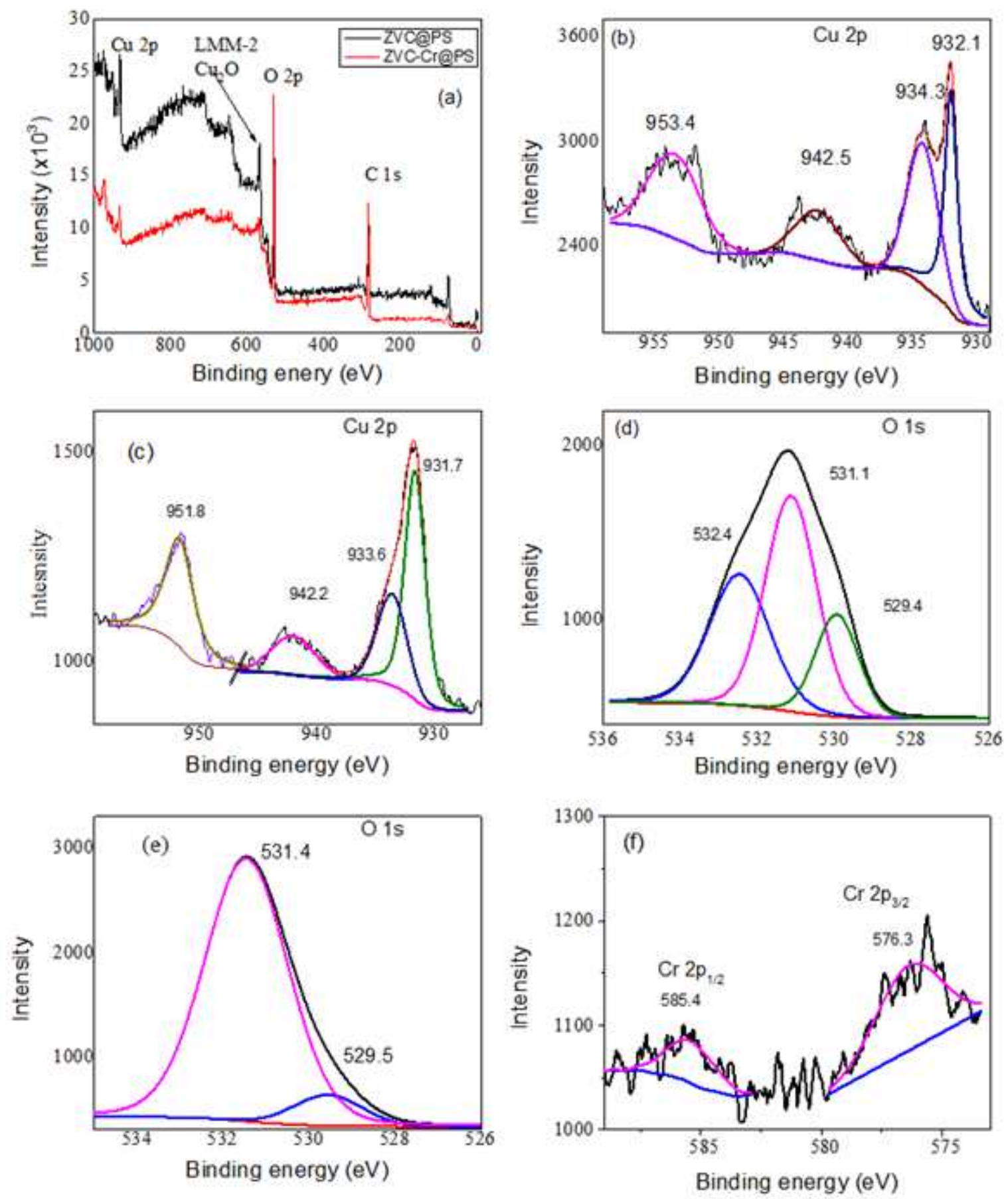

Figure 5

X-ray photoelectron spectroscopy spectra (a) survey scan of ZVC@PS; (b) Cu 2p before; and (c) Cu 2p after $\mathrm{Cr}(\mathrm{VI})$ adsorption on ZVC@PS; (d) 0 1s before; and (e) 01s after $\mathrm{Cr}(\mathrm{VI})$ adsorption on ZVC@PS 

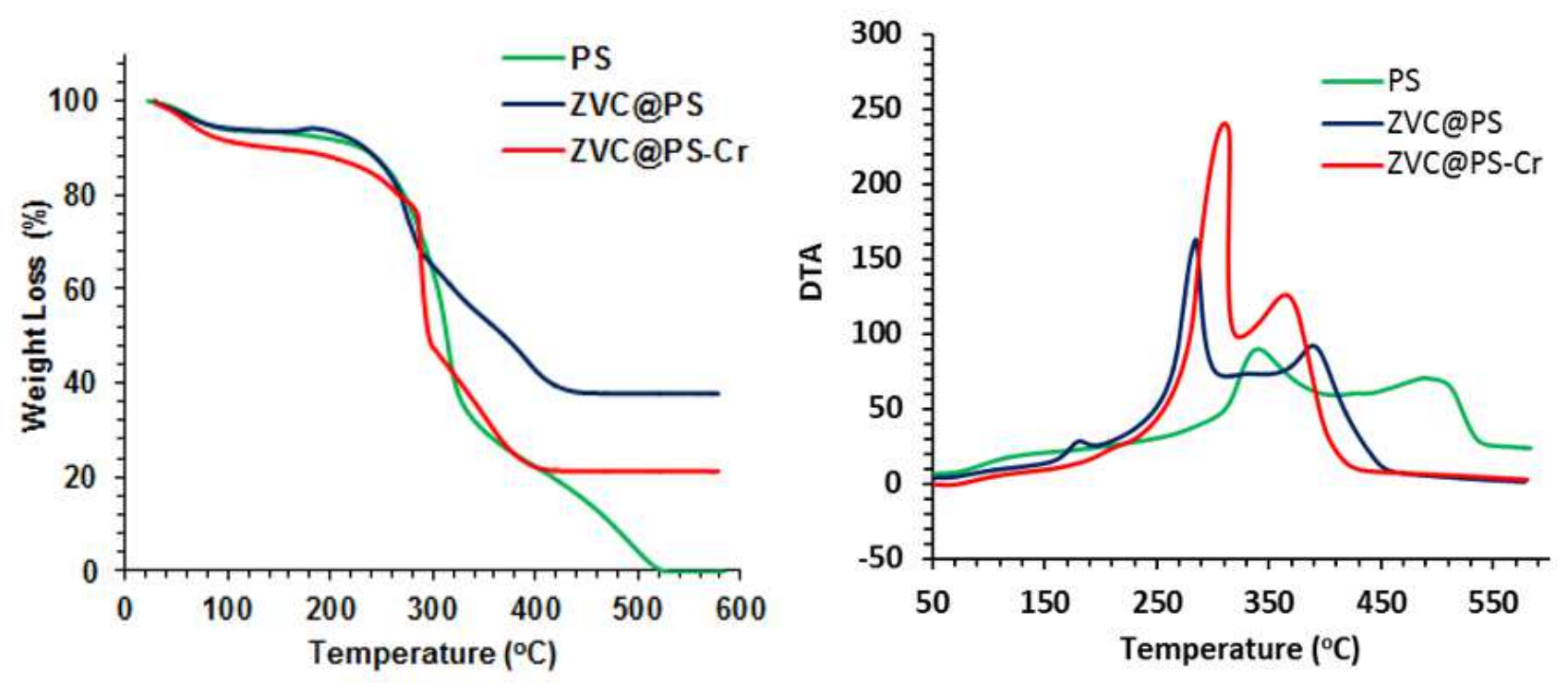

Figure 6

(a) TGA graphs; and (b) DTA curves of PS, ZVC@PS and ZVC@PS-Cr samples

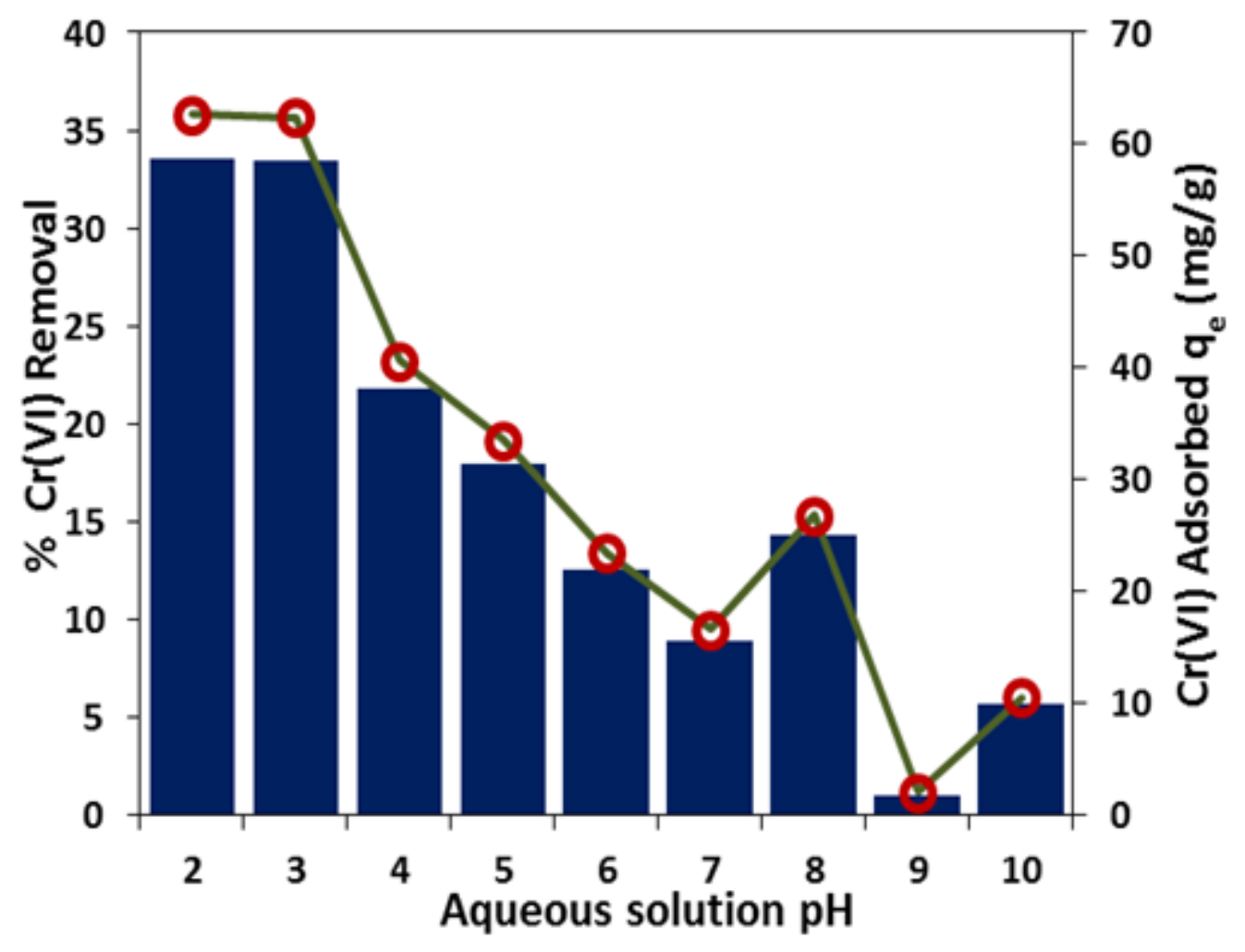

Figure 7

Effect of pH on $\mathrm{Cr}(\mathrm{VI})$ adsorption (qe) and \% Cr(VI) removal efficiency of ZVC@PS. [When ZVC@PS dose is $100 \mathrm{mg} / \mathrm{L}, \mathrm{Cr}(\mathrm{VI})$ concentration is $20 \mathrm{mg} / \mathrm{L}$, contact time is 24 hours, and shaking speed is $200 \mathrm{RPM}$ ] 


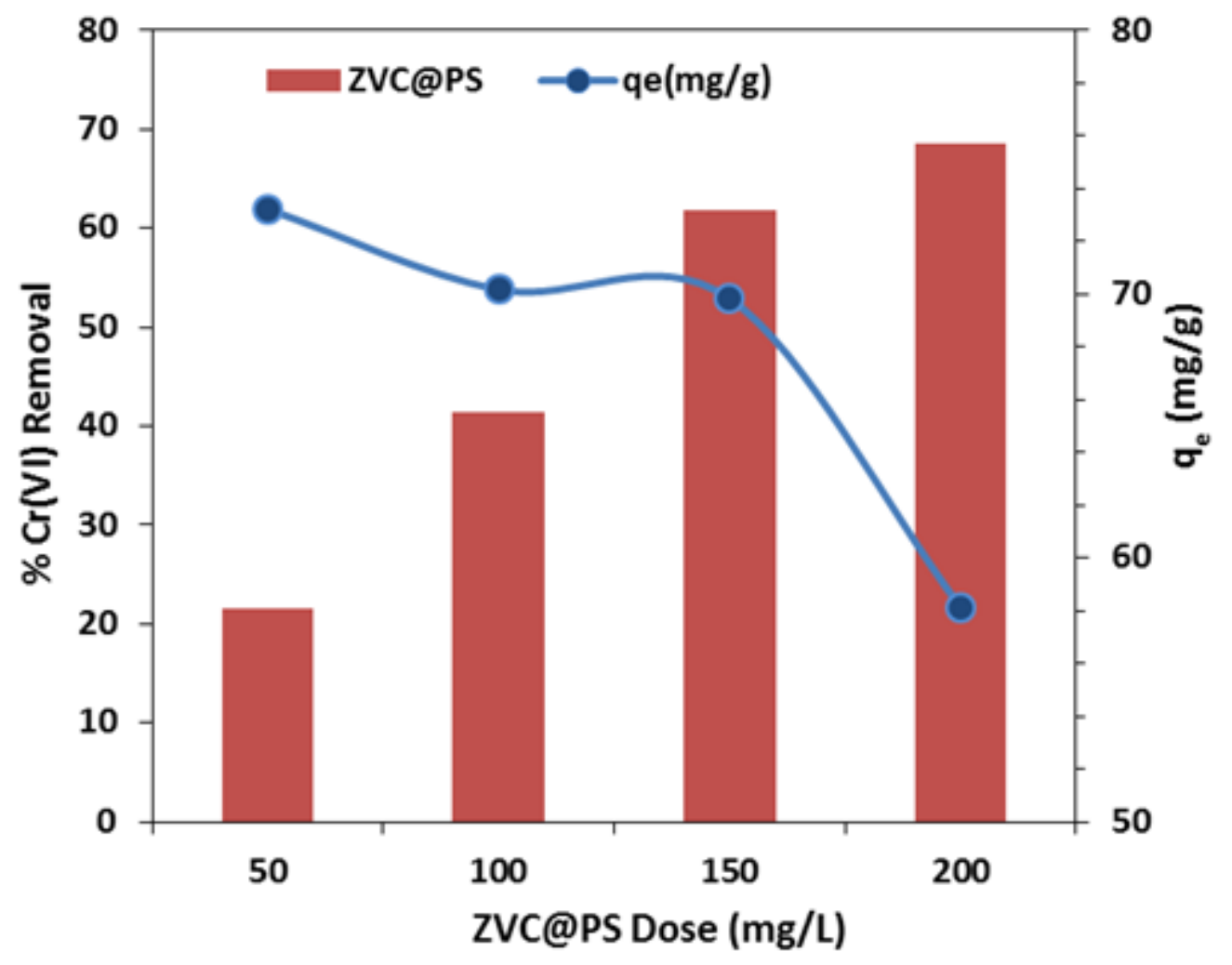

Figure 8

Effect of ZVC@PS dose concentration (50 to 200 mg/L) on $\operatorname{Cr}(\mathrm{VI})$ adsorption (qe) and \% $\mathrm{Cr}(\mathrm{VI})$ removal, upon treatment with $20 \mathrm{mg} / \mathrm{L}$ of $\mathrm{Cr}(\mathrm{VI})$ solution at $\mathrm{pH} 3$

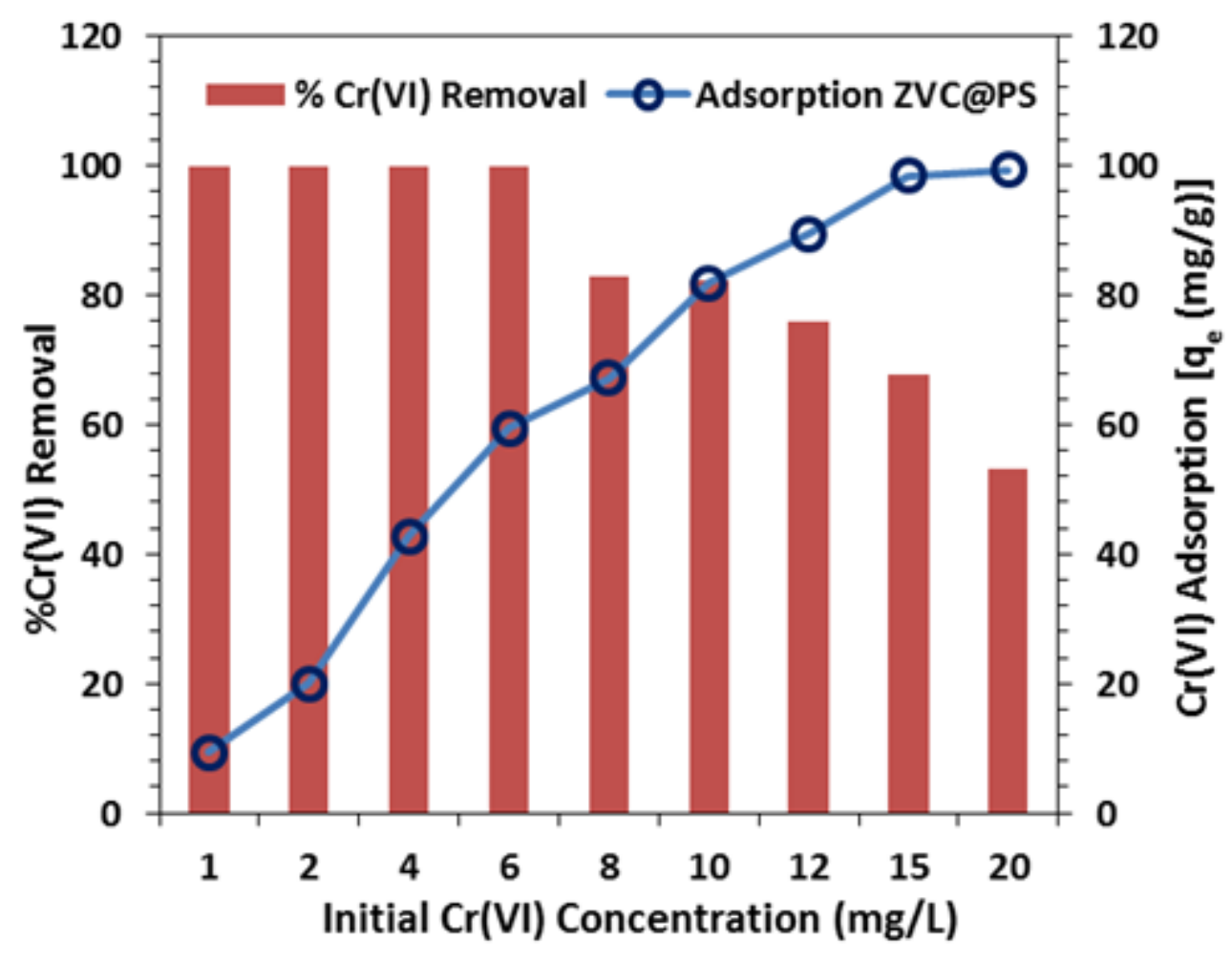

Figure 9 
Effect of initial $\mathrm{Cr}(\mathrm{VI})$ concentration (1 to $20 \mathrm{mg} / \mathrm{L}$ ) on $\mathrm{Cr}(\mathrm{VI})$ adsorption (qe) and \% $\mathrm{Cr}(\mathrm{VI})$ removal efficiency of ZVC@PS
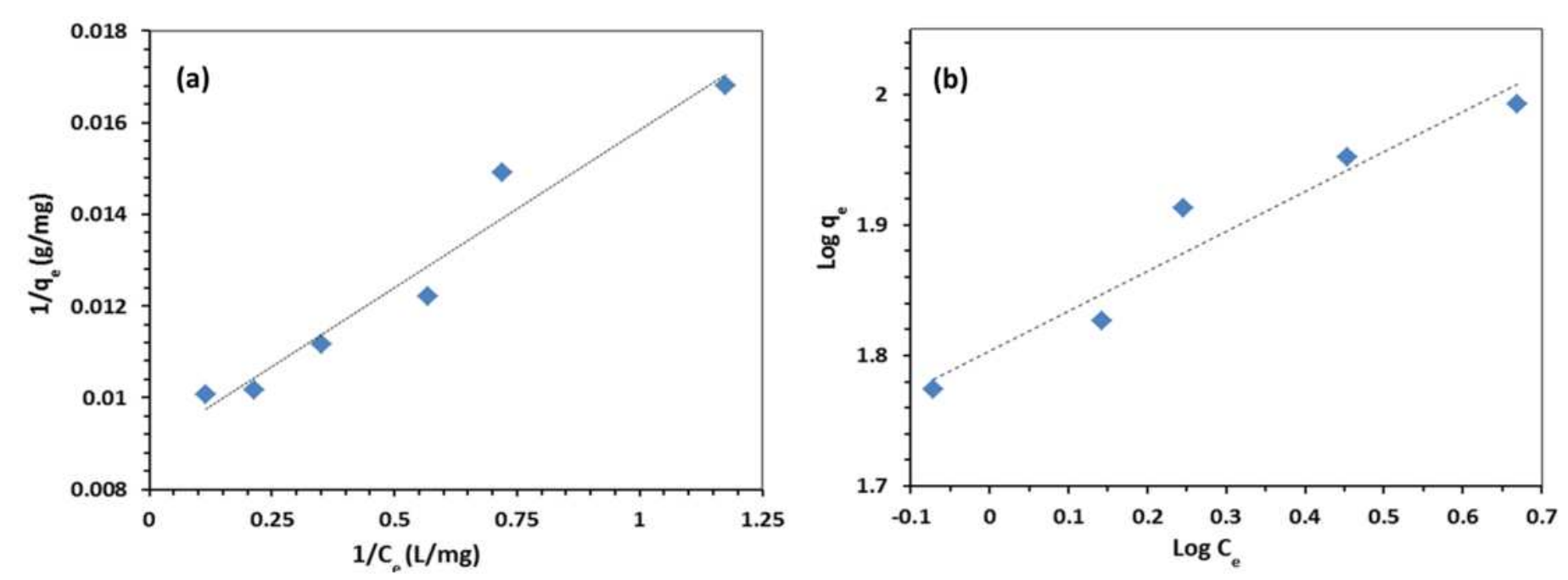

Figure 10

Langmuir adsorption isotherm (a); and Freundlich adsorption isotherm (b); for ZVC@PS for adsorption of $\mathrm{Cr}(\mathrm{VI})$
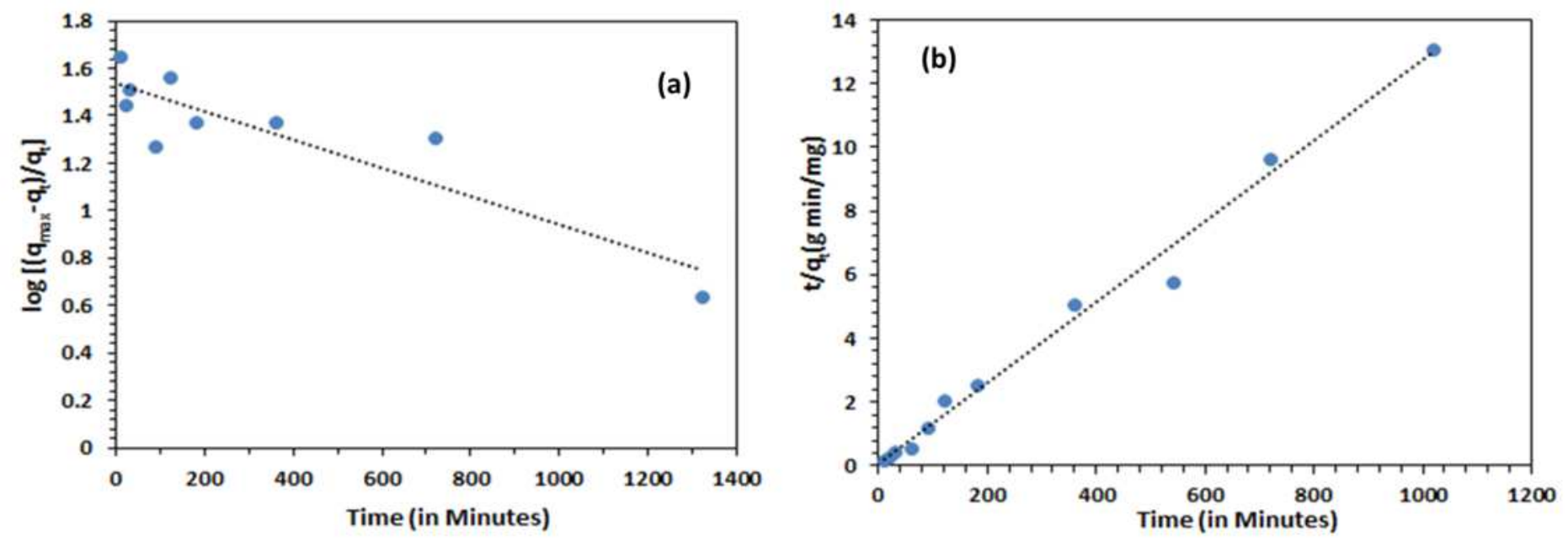

Figure 11

Linear fit plots of (a) pseudo first order and (b) pseudo second order adsorption kinetics

\section{Supplementary Files}

This is a list of supplementary files associated with this preprint. Click to download.

- GraphicalAbstarct.png 